\title{
Historical Creativities for the Teaching of Functions and Infinitesimal Calculus
}

\author{
Iran Abreu Mendes ${ }^{1,2 *}$ (D)
}

${ }^{1}$ Universidade Federal do Pará, BRAZIL

${ }^{2}$ Programa de Pós-graduação em Educação em Ciências e Matemáticas - UFPA, BRAZIL

*Corresponding Author: iamendes1@gmail.com

Citation: Mendes, I. A. (2021). Historical Creativities for the Teaching of Functions and Infinitesimal Calculus. International Electronic Journal of Mathematics Education, 16(2), em0629. https://doi.org/10.29333/iejme/10876

\begin{tabular}{|c|c|}
\hline ARTICLE INFO & ABSTRACT \\
\hline Received: 28 Jun. 2020 & This article presents reflections on a research that investigated processes operationalized by mathematical \\
\hline Accepted: 9 Jan. 2021 & $\begin{array}{l}\text { thoughts and practices which sought explanations for the ways of being of mathematical objects in their } \\
\text { correlations in the socio-cultural context throughout our human history and how these ways of being they were } \\
\text { captured, and still are, by the mind of those who exercised creativity in all the dimensions of mathematical } \\
\text { creation both in the past and in the present, in order to produce knowledge to be disseminated in the school and } \\
\text { scientific context. The research is a historical-epistemological study on mathematical creation, aimed at } \\
\text { characterizing modes of stages of this creation focusing on the development of infinitesimal calculus and on the } \\
\text { concept of function. At the end of the article, we propose educational guidelines for the teaching of these } \\
\text { mathematical themes, based on the creation processes announced throughout the text. }\end{array}$ \\
\hline
\end{tabular}

Keywords: creativity, mathematical creation, mathematical history

\section{INTRODUCTION}

A question frequently established in educational environments and in the contexts of the academies of sciences and arts refers to the act of creation, with the purpose of conceiving creativity as a skill inherent to human beings in their process of knowing, explaining and understanding. Such inquiring concern leads to two questions: why and for what purpose? In this regard, several scholars of the subject assure us that creativity is an essential human skill to be exercised, because it is essential to the development of the potential of those who study, learn, and produce knowledge. Such a skill is essential for human autonomy in the sense that it helps us to develop innovative/creative thinking in the production of new knowledges that imprint a constant interest in the renewal and aeration of ideas.

This article presents reflections on the multiple processes operationalized by mathematical thinking and practices in search of explanations for the way of being of mathematical objects in their correlations within socio-cultural contexts throughout our human history and how these ways of being were and still are captured by the mind of those who exercise creativity - in the past as well as in the present - in all the dimensions of mathematical creation, in order to produce knowledge to be disseminated in the school and scientific context.

To initiate any reflection on creativity, it is important to bear in mind that we should not think of it as a human skill originated from an exclusively individual phenomenon or act, but rather as a systemic process in which social interaction is always fundamental, as Csikszentmihalyi (1996) argues when dealing with invented or discovered knowledge in its ways and systems. Such an assertion means, therefore, admitting that, in order to be creative, it is necessary to make use of divergent or creative thinking, that is, an exercise to think creatively, in order to establish coherent connections with the context in which ideas are being inserted into society and the cultural world, that is, through a process of validating ideas produced in a socio-cultural context.

To exercise divergent thinking in order to be creative refers to the fact that it can be provocative, paradoxical, metaphorical, playful with one's own thinking, thus exercising its flexibility to always find the best options and the best paths for any and all situations, both personal and professional. In this perspective, to think in a creative way means to generate alternatives, to face challenges, to discover solutions, that is, to use various resources that enable us to go beyond what we imagined to be possible, as suggested by Araújo (2009), when discussing creativity in education.

If we consider that there are some systemic models of creativity, the theory of an investment in creativity is seen as the convergence of six distinct factors that are also interrelated to intelligence, intellectual styles, knowledge, personality and 
motivation, thus causing the emergence of an environmental context in this chain of factors, one in which the creative process can occur at varying levels. However, the characteristic of a social context conducive to creativity is evident to the extent that this context contributes to stimulate creativity itself, so as to involve not only an individual, but to also affect his socio-cultural environment, including the people who inhabit it.

If those who surround the individual do not value the creative act, do not offer a necessary supporting environment, do not accept creative work when it is presented, then it is predictable that the individual's creative efforts will encounter insurmountable obstacles, as highlighted by Stein (1974). However, a journey of confrontation to overcome such obstacles becomes a challenge. Thus, the historical facts about creativity and innovation justify the avant-garde exercise of its creators when facing obstacles, such as Lewis Carroll in his logic of nonsense, Descartes (1637) in his algebraic geometry and Alan Turing in his thinking machine.

The search for answers to some of the questions that were mentioned earlier refers to the act of creation and its relationship with the tree of knowledge, in order to understand that

(...) the knowledge of knowledge forces us to assume an attitude of permanent vigil against the temptation of certainty, to recognize that our certainties are not proof of the truth, as if the world that each one sees was the world and not a world that we build with other people. It forces us, because when we know that we know, we cannot deny that we know (Maturana \& Varela, 2001, p. 267).

It is this vigil mentioned by the authors that allows us to constantly ask ourselves about the inclusion of new outlooks, reflections, new concepts about the knowledge we produce about things and about the search for new reflections on the conclusions previously established by others, in order to set up the creation process, which turns the production of knowledge into an action-reflection-action movement, one in which $99 \%$ of it consists of perspiration, and $1 \%$ of it is creativity ${ }^{1}$. This numerically small portion, which is evidenced in the production of knowledge, means an addition immersed in tradition, innovation, and renewal, as suggested by Gonçalves-Maia (2011), as well as an addition through trance, art and creativity, as Vergani (2009) mentions, highlighting that the prohibition of trance and the elitization and commercialization of art left only creativity as a possibility of giving the world the opportunity of acquiring knowledge by means of knowing themselves.

Still on this topic, the tree of knowledge that underlies the discourse on the method proposed by Descartes (1637), makes us reflect on a creativity process in the search for solutions to problems of explanation of natural, social and cultural phenomena, in the relationship that the establishment of general and secondary issues has to solve a problem. In general, in the course of scientific and socio-cultural practices, problems started to be taken into consideration only from the stem of this tree, then from the branches and finally only from the leaves, until the focus was given only to the flower and the fruit.

As I mentioned earlier, a new look at the tree of knowledge, given by Maturana and Varela (2001), reflects on the need to look with the whole brain and from the largest possible number of possible approaches, as long as they are interconnected, in order to give a broader and deeper sense about the object currently under construction. Following, still, in that same judgment about the creative process, Serres (2008) leads us to reflect that the new branches originated in the tree of knowledge refer directly to the portion of this $1 \%$ of creativity which I mentioned earlier. For Serres (2008, p. 81), "the branch does not kill the stem, but it rests on it, even if to get away from it". However, necessarily, such a departure should not mean disconnection. The author also states that the connectivity originating from the information of the virtual communication networks and the practice of informationism, quite common today due to virtual research, can cause the inhibition of the branches in the tree of knowledge.

It is possible, therefore, to admit that human society has a cultural dynamic that is characterized by a process of continuous rethinking about its way of producing knowledge, that is, about the ways of creating and operating thinking strategies in the production of knowledge within a cultural context. It is, therefore, an exercise in creativity that has a direct implication in the development of autonomy in the searching spirit of those who investigate and create.

I define this searching spirit as a spirit of the researcher, which I always refer to talk about research as a teaching and learning principle, since I understand that this investigative spirit was what ignited my personal and professional development throughout my training as a teacher and as a researcher (Mendes, 2015). I believe, therefore, that by exercising this searching spirit, this attempt to exercise creativity, we are able to advance in the construction of our intellectual autonomy as a person who wants to learn.

Creativity, therefore, is a skill inherent in scientific and educational activity. Therefore, it is necessary to seek answers to some questions such as: what is creativity? How is a creative personality formed? How to describe and characterize creativity, considering the need to mobilize a set of cognitive skills to produce something new or new knowledge about any objects in the world? To address argumentative aspects about creativity as a manifestation of human cognition in search of the formulation and support of truths in its globalizing scope of human thought, experiences and reflections, I immediately refer to the ideas present in two works by Domenico de Masi on creativity, entitled The creative leisure (2000) and Creativity and creative groups (2003). Both works have as their main focus the human capacity to continuously create and reinvent themselves in the world. The theoretical density and the conceptual and epistemological richness of the second work is essentially important to studies on the production of knowledge in its multiple aspects, as I mention below.

De Masi (2003) asserts that in the relationship between human discovery and invention, it is possible to affirm that our society has created justifications for some natural processes and phenomena based on arguments such as "the seven days of creation". In this same spirit given to the first explanatory attempts on human discoveries or inventions, the author states that, according to

\footnotetext{
${ }^{1}$ This expression appears in the literature on the subject of creativity as belonging to several philosophers, scientists or thinkers, such as Thomas Edison.
} 
the challenges that arose historically, when man discovers imperfection he invents the word and when discovering symbols, he invents the beyond. During his socio-historical process, he discovered the seed and then invented the State. When he discovered iron, he invented fatigue and when he discovered wisdom, he invented leisure. He discovered purgatory and invented himself; discovered precision and invented the industry; discovering creativity, he invented the future.

Still on these relationships and human creativity, De Masi (2003) ensures that in the attempt to relate fantasy and concreteness, as two factors that generate human creativity to make sense of the realities invented by our society, several contributions arise from the neurosciences, from psychoanalysis, psychology, epistemology and sociology. In this perspective, therefore, it is necessary to consider, mainly, the rational and symbolic paths that allow the establishment of creative synapses that are characteristic of this creative process that institutes the inclusion of new concepts to the study of old problems, whether in mathematics or in any other area of knowledge one wishes to investigate, especially when thinking about the knowledge generated in a network of globalizing connections established in society and culture. For a creative process to be productively installed in the generation of knowledge, such as happens with mathematics, an initial preparation is important, that is, the organization of a challenging and stimulating context of human creativity, which can trigger our cognition and lead us to a reorganizing and innovative exercise in the formulation of explanations for the investigated problem.

The creative process, then, begins to take shape, definition and descriptive and explanatory convergence as the actionreflection-action continuum leads us to perceive new conclusive points about the new way of building the object of our knowledge. Therefore, there are three important moments in this creative process: the insight, the examination, and the communication of the produced idea. The creative process does not proceed in a systematic and organized manner from beginning to end. The steps do not necessarily follow a linear sequence, for they can develop according to the stimuli and challenges caused by the environment at each moment of the cognitive action of those who exercise creation. The success of the creative act depends on favorable conditions for creation, such as the availability of time and resources, since intrinsic motivation is an important factor and, in the course of the creation process, modalities of conjugation of cognitive and affective aspects can be observed, which leads to the expansion or not of the creative exercise.

Another decisive factor in mathematical creation is the knowledge that each person has about the theme they will investigate in order to produce knowledge, that is, about the transversal aspects mathematics nourishes itself from in order to configure itself continuously. This kind of information, connected to the mathematical knowledge that one intends to describe, explain, and formalize, becomes essential to the development and implementation of new ideas. However, some metacognitive strategies are needed, such as monitoring and evaluation, which can be used at different stages of the process.

Therefore, some questions are left to us, regarding the epistemological foundations concerning the creative processes related to mathematical creation, such as, for example, the characteristics of creative activity in mathematics and its components; the concept of mathematical imagination and invention; the connections between creation, invention, and innovation, as well as about conceptual extension through creative processes in mathematics. In this regard, we will address theoretical aspects in the following sections of this article. Initially, we will address some epistemological foundations established by authors who have dedicated themselves to this theme since the end of the 19th century, as well as the conceptual developments arising from these studies which have led to processes of creation and innovation in mathematics, such as the current studies related to the connections between mathematics and art.

\section{ON CREATIVITY AND MATHEMATICAL CREATION}

The theoretical foundations that support the discussions presented in several articles and books that I have published since 2001, almost always converge to the use of investigative principles in learning, that is, they address what is research, how to practice it, how one learns through investigation, how to attain knowledge through investigation, among other epistemological aspects about these principles. In these articles and books, such ideas appear as theoretical matrices on which I rely to enter into a dialogue with principles that support my research on the History of mathematics and Sociocultural Practices, with the object of drawing epistemological foundations for the teaching of mathematics in Basic and Higher Education.

Such ideas reveal directly or indirectly formative aspects that converge to transdisciplinary thinking in a way similar to that in which some scholars conceive that the production of mathematical culture provides conjugated ideas about a given object of knowledge without being constrained to epistemic limitations concerning the ways of conceiving, understanding, and explaining this cognitive object which is in continuous construction, that is, it's always in the process of creation in someone's thought, actions, and reflections. This is because the socio-cultural dynamic, which is a feature of humanity, never ends; and since it never ends, there will always arise aggregating elements to allow us to make a new characterization of what can be explained as mathematical culture that is materially or immaterially established through a process in which creativity is essential.

And the most important thing is that this dynamic of creation justifies the same epistemological configuration that mathematics exhibits in all its historical development, as well as its epistemological behavior as an imaginative, inventive and innovative game that is organized through its own combinations and rigors in language and technique - I would say it is a type of composition that never closes, to provide new processes of creation and conceptual expansion, although the socio-cultural representation of mathematics makes some meanings emerge, such as "a calculation" (an algorithmic expression that involves arithmetic or algebra), as "a geometric shape" (a geometric expression that involves measurements, proportionality or geometric constructions), and other expressions like these. However, the epistemological composition of what can be conceived as mathematics has a dynamic that gives rise to multiple logical combinatorial games, so that there's always room left for further explanation, to expand senses and meanings, and thus broaden the field of mathematical creation. 
In my understanding, mathematical culture has a epistemological composition that is in continuous formation, because it always resorts to the sociocultural dynamics of knowledge production at its multiple levels (society, school, science, technology, religion, etc.), whose epistemic combinations are organized in a logical way, so that this knowledge that we call mathematical knowledge broadens our outlook regarding the ways in which different social groups can enunciate certain social views about what we call mathematics.

Therefore, it is a matter of proceeding in exercises of looking at the way society produces its ideas, its readings of the world, an exercise which becomes enriching, allowing us to imagine more possibilities of dialogue with the world. This is the most important thing when we enter a path of understanding the cultural dynamic in which mathematics is inserted. Perhaps it is on this human principle, which makes it also a sociocultural principle, that the whole epistemological basis of mathematics is based. It is not a matter of abandoning a formalized look, but of admitting that we have a single and multiple view, that is also singular and plural, therefore an imaginative and inventive one, that strips us of our technical thinking to borrow the playful thinking of others, which is also a way of looking at things. And when we ask another person's outlook so we can also look at things, we start to create possibilities to have all sorts of eyes with us to see them.

And in this case, this movement sustained by the socio-dynamics of cultural gazes is what gives mathematics a transdisciplinary character, as these outlooks are present in the histories of mathematics produced in times and spaces, giving rise to points of epistemological support, as we can see in the histories of human culture, in general, always with possibilities of looking and borrowing various outlooks so that we can have a greater amplitude regarding the object we want to look at. This is the characteristic way of transdisciplinary, complex thinking, and historically produced mathematics is also accomplished by means of this outlook. If we do not exercise it, we can hardly produce mathematics as a human culture. Because if we restrict our gaze, we will lose many aspects that are to be observed and, therefore, reflected on. So, this is a main point, namely the epistemological basis for thinking about human mathematics in its diversity and at the same time in its uniqueness, its singularity, and its plurality.

It is with this principle that we can approach the process of creation or invention in mathematics. To do that, we can start from the ideas Poincare (1908) advocated for the formulation of arguments based on the fact that the genesis of mathematical creation is a problem that should inspire the psychologist's most keen interest, since it is a human cognitive action of processing ways of understanding and explaining facts that shape the ways of existence of the outside world and the internal organization processes of this understanding and explanation within each human in their own sociocultural communication processes. However, there is a provocative question in Poincaré's discourse: what, in fact, is this mathematical invention?

For Poincaré (1908), it is not just a matter of making new combinations with mathematical entities which are already known, since anyone could make them and thus be able to obtain a finite number of results. Therefore, inventing does not mean only combining in order to generate things that are sometimes useless but also to produce in order to be able to make useful choices. In this sense, the author asserts that the mathematical facts worthy of being studied are those that, by analogy with other facts, can lead us to the knowledge of new mathematical theories as well as the experiments allow us to better know the foundations of the knowledge of the physical world. Poincare further asserts that the invention occurs as if the inventor were a second-level examiner, who would not have to interrogate any but the candidates declared eligible after a first test.

Next, I will discuss some aspects of mathematical imagination and invention as a creative act, based on some authors such as Poincaré (1908) in the book Science and Method, Hadamard (2009) in his Psychology of Mathematical Invention, Boirel (1966) in L'Invention (The invention), Moles (1957) in the book La création scientifique (The scientific creation), Bohm (2011) in On Creativity, Steiner (2011) in Grammars of Creation, David Perkins in The Archimedean Bathtub and other stories of discovery and Csikszentmihalyi (1996) in the book Creativity: the Flow and Psychology of Discovery and Invention, among others who have dedicated themselves to this subject.

Finally, I also intend to mention a few notes on some pedagogical perspectives regarding creativity in teaching work proposals, mainly in the sense of developing creative skills in students in their educational processes.

\section{Imagination and Invention as a Creative Act}

A conceptual discussion about what can be considered as a scientific or mathematical invention has been established since the end of the 19th century as an explanatory action, whose propositions of validity parameters were attributed to logicians, when they launched their rules of rigorous reasoning connected to the experimental method to guarantee "scientific validity" to the knowledge produced by human society, mainly in academic communities. Therefore, in this respect I refer to the different logical and methodological processes established in the processes of scientific invention, specified in different scientific fields. As I mentioned earlier, an example of this appears in the work of Henri Poincaré in 1908 when he published the book Science et Methode (Science and Method).

It is from this way of thinking about this subject that many scholars who research knowledge production admit that the stages considered in scientific creation have been more clearly highlighted by scientists over the past three centuries (1800-2000) than those of artistic creation. However, it was from the second half of the twentieth century, at the epistemological turn marked by the advent of discussions on interdisciplinarity, followed by transdisciplinarity and complexity, that we see a broad expansion of the dialogues on scientific creation in a pre-paradigmatic approach, according to which there is no way of limiting the boundaries of the epistemological process in the scientific production of knowledge, through which discussions and reflections on this subject have been expanded, as well as the ways of reinventing scientists' research and knowledge production practices in their ramifications in the scientific field to welcome these new investigative referrals.

In the book L'Invention (The Invention), Boirel (1966) already argued that scientific invention is simpler, in a sense, for the philosopher who studies it, than artistic creation, given that in art we have a convergence of all human possibilities - affectivity, 
imagination, and manual skills, whereas in scientific invention there is a tendency to take into account essentially the work of human intelligence, centered on logic-based rationality, that is, on the exercise of rational logic (without imagination). Therefore, the following questions arise from this premise: what are the modalities of invention in the various sciences and in mathematics?

At first glance, it seems that the invention of mathematics is a rational science par excellence, the result of which denotes rigorous deductions. However, this is not the case, and this illusion of absolute truth comes from the fact that we rapidly confuse the types of mathematics that are formed and taught and the types of mathematics that are practiced. For Boirel (1966), the mathematician, in the presence of his problems, does not know a universal key to solve them. In fact, he must constantly imagine new processes. To produce an example of this behavior, the author quotes Pascal, who invented an instrument intellectually suited to the exploration of each question he addressed: for the study of conics, he invented the mystical hexagram, for the calculation of probabilities, he coined the arithmetic triangle.

Thus, it becomes understandable that mathematical research has not followed, does not and will not follow a unique and predictable trajectory in a certain deduction of itself. What is historically identified is that there has been and always will be some surprising approach to mathematical production. In this sense, based on Boirel (1966) I can exemplify with the fact that all the obstacles found by the researchers that opened the way for infinitesimal calculation, if analyzed and reflected on, will constitute a proof that it is only after a long time in the darkness that the mathematician finally sees a steady stream of clarity in his ideas ${ }^{2}$.

If we consider that there is no exclusive and unique deductive method to invent in mathematics and if, likewise, the development of mathematics is linked to the unpredictable, it is because the basic notions are not absolutely clear, that is, we cannot say a priori what will be, nor where will be the end point of the critical work process that replaces the obscure information of the notions of intuition, clarified in the analysis and reflection on the information produced by the imagination and by creative experimentation.

In this regard, is it possible, for example, to ask why several mathematicians have not tried in vain for many years to solve equations of degrees greater than four? The answer appears in the history of equations only at the beginning of the 19th century, when Abel stated that these equations were not solvable by radicals. Thus, new paths were designed and followed in an investigative manner, with the support of curiosity, creative imagination, and a lot of experimental work based on the mathematics produced until then, in order to obtain acceptable answers to the problem.

However, if mathematicians are faced with the opacity or nebulosity of certain mathematical notions, by their own conviction and insistence, they can sometimes arrive at the formulation of theorems that are revealed by unexpected fertility. For example, when Augustin-Louis Cauchy (1789-1857) invented a systematic explanation of the imaginary from works of other mathematicians such as Girolamo Cardano (1501-1576), Rafael Bombelli (1526-1572) and others among his predecessors, his contemporaries were far from suspecting that this knowledge would be used in a number of problems and even in real number theory. Thus, we admit that mathematical research is full of unforeseen events because it follows a method very close to the experimental method, given that the mathematician, like the physicist, risks a hypothesis, which is the result of a first empirical generalization, and then strives to verify properly the conclusions obtained. From these experimental conclusions, it becomes possible to raise new hypotheses that enable the conclusive expansion and from there act creatively in the sense of generating expanded elaborations on the "mathematical facts", and their structures.

For Bohm (2011), the creativity process seems to be something very difficult to define, since it is not only a special talent, but an ability to free the mind in order to be more attentive, alert, aware and sensitive to the facts so as to enable imagination, creative invention and the discovery of new facts and their correlations with existing ones, that is, the establishment of a new order of explanation for new structures of concepts and ideas.

In this regard, Steiner (2011), in his grammar of creation, proposes that currently the concepts of creativity and invention are always conceived in contextual processes, that is, their semantic field belongs to history, due to their socio-cultural, psychological and material components, since that which means to deal with eternity is itself linked to time. Likewise, Steiner stresses that the invention, due to its contactable and constitutive linearity, is rigid and is the engine of historical time, that is, the relations between the experience of temporality, the sequential calendar of stories, and the idea of creation are, in comparison, enormously disconcerting.

For Perkins (2003), however, what essentially matters is not creativity in general, but the progress of thought as a direction towards the break with what belongs to the order of the past, that is, the transformative addition to what it's already established. Therefore, it is about surprisingly advancing the creation of ideas and products that are useful to the expansion, innovation and renovation within an already established framework. Nevertheless, Perkins (2003) characterizes this process as a leap of thought in the breadth of imagination and in the reduction of cognitive blindness, through four essential operations: exploration or wandering, detection, reconsideration or reframing and lack-of-focus or decentralization. These operations refer fundamentally to the processes of seeking and producing knowledge through thought strategies and actions exercised in research and learning. It is up to each person to exercise such operations according to the conditions offered by the context in which the object that is to be known requires from the researcher, causing him to exercise his imagination and create paths to reach the final point.

Regarding this subject concerning creativity, Abraham Moles $(1957 ; 1998 ; 2007)^{3}$ elaborated a study called Scientific creation, in which he deepens his epistemological propositions and discussions about scientific creation, stating that it is a matter of studying the process of intellectual creation from a philosophical and scientific angle, because he considered the concept of

\footnotetext{
${ }^{2}$ Following this article, I will present an example of this creative dynamic in the history of mathematics from the history of infinitesimal calculus and the concept of function.

${ }^{3}$ The first edition of this book in French is from 1957, with its first reprint in 1998. The Brazilian translation is from 2007.
} 
creativity as an aptitude of the spirit to reorganize the elements of the field of perception in an original and susceptible way of giving rise to operations in any phenomenal field.

Likewise, Moles (1970) asserts that creation is the process through which a new object is brought into existence, because he considered that creativity is a skill of the spirit (mind) that includes the ability to create and that creative productivity it is a quantum of novelty per unit of time; This is because the creative force will remain in the moment, as a metaphor that justifies itself when necessary.

In this sense, Moles (2007) mentions that, historically, three types of scientific truths have emerged concerning three groups of sciences in different stages of development: science of what is right, science of what is probable and science of what is perceived, caused by creative processes established by the scientific spirit in time and in space, admitting that there is no difference between pure and applied science, but a dynamic that moves in thought looking for echoes, that is, for contexts to establish itself as creation. The author also points out that there is a difference between formalized science, which we find registered in texts, and scientific creation, given that scientific creation advocates ways of chaining a priori judgments in their relations with established concepts, in search of establishing new concepts.

From a closer perspective of cognitive and pedagogical processes in relation to mathematics, Gontran Ervynck (1991) chooses as foundation some teaching experiments on mathematics teaching, reinterprets the ideas of Jacques Hadamard, makes an attempt at theoretical elaboration and presents a definition of what he considers mathematical creativity enunciating it as:

(...) the ability to solve problems and / or develop thinking in structures, taking into account the peculiar logical-deductive nature of the discipline and the adequacy of the generated concepts to integrate themselves into the core of what is important in mathematics (Ervynck, 1991, p. 47).

Ervynck's attempt to define mathematical creativity makes it clear that it is centered on the problem solving perspective taken as the central concept of this definition, albeit in correlation with an axiomatic method of organizing a theory. Therefore, it refers to the human capacity to address a challenging situation in search of solutions for it, reiterating the proverbial strength mentioned in the introduction to this article.

Therefore, I reiterate my reflections on the need to establish concepts and propositions related to the objects that will be created so that they can be elaborated with sense and meaning, according to the reality we want to build, or the solution we want to present in any problematized situation. Based on this definition of creativity, this is how objects come into existence, as well as how their properties and relationships with everything that is established are formulated at each stage of their construction.

However, other conceptions and definitions of creativity and mathematical creation, assumed by different epistemologists, have led to the emergence of other ways of thinking, doing, and teaching mathematics since the early days of the existence of academies and schools. Examples of these ways of thinking and doing mathematics are exposed in publications by authors such as Kasner and Newman (1968) on the processes of changes related to mathematics and imagination; Kline (1985), regarding criticism of the certainty attributed to mathematics throughout its history; Lakatos (1978), regarding the heuristic application to the creation of new mathematics in both the academic and school environment; and Davis and Hersh (1995) on creativity in mathematical experiments, among others.

In this regard Davis and Hersh (1995) consider that there are some central elements of creativity, such as an analytical capacity, based on a combinatorial or geometric visualization skill that develops a mathematical aesthetic, as advocated by Poincaré in Science et Methode (1908). It is this aesthetic that often acquires a comparative sense in order to establish a better adequacy of the existing knowledge to operate the creative generation of the new knowledge, as is the case, for example, of a mathematical proof or demonstration. It is a comparative aesthetic that selects what is considered most appropriate to our visual, combinatorial and analytical skills to explain what is imagined, technically combined with what we want to achieve. Perhaps it is this creative exercise that characterizes the algebra of François Viète (1540-1603) and the geometry of René Descartes (1596-1650). It is possible to think about the procedural trajectory of this dynamic of mathematical creation, as we will discuss below.

\section{CREATIVE PROCESSES IN MATHEMATICS ACCORDING TO GONTRAN ERVYNCK}

For Ervynck (1991), the process of mathematical creativity does not materialize from nothing, that is, presumably mathematical creation cannot occur in a vacuum. This creation needs to be operationalized before, based on a previous experience already established, so that innovation occurs, that is, a significant advance of the object of knowledge, in a new direction towards a bifurcation. It is a preparation that happens based on previous activities, which form an appropriate environment for creative development. The author's hypothesis is that the context for the creativity exercise requires a preparatory stage in which mathematical procedures can be used in early stages, when procedures can be performed in order to obtain a complete appreciation of the theoretical status to which one intends to or is able to achieve. In this sense, Ervynck (1991) takes into consideration the existence of three stages for the development of creative processes in mathematics, as I will mention below.

\section{Stage Zero: A preliminary stage or technical trend}

Ervynck's hypothesis (1991) is that mathematical creation can originate by means of a preliminary invention stage, that is, from a technical or practical application of already known mathematical rules and procedures, without the user being aware of its theoretical foundation. In this case I consider it to be the art of the artisan mathematician, who uses a set of mathematical procedures as a toolkit. The reason for this procedure is that the practitioner has empirically verified that it works, in the sense 
that it has an adequate application to obtain a desired result. An example of such a practical procedure is the rule used by rope stretchers in ancient Egypt and Mesopotamia to establish a right angle, when they used a line with marks dividing it into three parts of length 3, 4 and 5, forming the sides of a right triangle; This operation is still widely practiced by bricklayers.

I emphasize that there are many examples in the history of mathematics that characterize this phase, called preliminary stages, such as the mathematical practices of Abacists, the activities related to practical geometries and, in general, the geometric constructions built with ruler and compass. Likewise, the mathematical determinations established from socio-cultural readings and practices present in the almanacs, among others, such as the Lunário Perpétuo, as well as the creative process of astronomicalmythological arithmetics used to settle several calendars in all times and cultures. In this sense, some examples of mathematical processing are discussed by Duncan (1999) in the book Calendar: the epic of humanity to determine a true and exact year ${ }^{4}$.

\section{Stage 1: Algorithmic Activity}

According to Ervynck (1991), from a preliminary stage related to mathematical creation, progress normally advances in this creation through an algorithmic activity, and it is at this stage that procedures are used to perform mathematical operations, calculate, manipulate, solve, that is, the activities are essentially concerned with performing mathematical techniques. Examples of such techniques are the application of an algorithm, the creation of formulas, the factoring of a polynomial, the calculation of an integral computational activity involving computer programs, as numerical methods to solve differential equations, all disconnected from any sort of socio-cultural context except the mathematical context of the activities. A characteristic of such activities belonging to this stage is that they are not clearly explained. Therefore, all intermediate steps must be considered, at least implicitly, for a serious error can occur and totally invalidate the result. In the case of a computer algorithm, no steps, not even trivial ones, can be overlooked. There is no regeneration of missing steps in an algorithm. The guidance given by John Wallis in Arithmetica Infinitorum, as well as by Girolamo Cardano and Nicolo Tartáglia, and Joseph Louis Lagrange, in the methods of solving equations, seem to characterize this stage.

Such activities can be considered part of an advanced mathematical process, but they can also be seen as part of a general theory of mathematics, because these processes must be integrated into the minds of those who create and those who take any mathematical creation to appropriate it. We can mention as a historical example the procedures established in Vedic mathematics, the algorithmic rules for determining the roots of an equation when they are proposed step by step without any justified conceptual meaning. The same refers to the procedures related to geometry activities when they are guided by purely automated steps, without any conceptual justification for the indicated procedures.

\section{Stage 2: Creative Activity (Conceptual, Constructive)}

For Ervynck (1991), creative activity, when properly admitted, corresponds to a more advanced stage that involves a movement towards a conceptual and constructive establishment. It is at this stage that creativity in mathematical creation can turn to the development of a mathematical theory, since it is a non-algorithmic decision, which is considered to demonstrate the significance of a bifurcation in the existing conceptual structure, that is, an innovative conceptual expansion. In this case, mathematical creativity is conceived as the ability to carry out these steps, whose procedural decisions must be made on a caseby-case basis and therefore are liable to vary widely, and may be subject to the choice of a certain concept, or to a decision to declare and prove a theorem.

Based on studies developed by me since 1993 on the history of mathematics and its relations with teaching, I can assert that there are several creative historical moments in the history of mathematics that could be characterized in the three stages designated by Ervynck (1991), to understand and explain mathematics as a continually expanding theory. I can mention, for example, the development of theories on geometries, from pre-Greek practical geometries to algebraic and non-Euclidean geometries, as well as the studies that triggered the creation of infinitesimal calculus and its subsequent ramifications until analysis, involving directly the concept of function to a general theory of functions.

For many readers who do not have in-depth knowledge of the historical development of mathematics, it seems to be little understandable to imagine multiple trajectories of a mathematical creation from its conceptual embryo, originating many times in apparently non-mathematical practices which give rise to curiosities, challenges, problematizing questions, and that have led (and still do) artisan-mathematicians, algorithmic-mathematicians and theorist-mathematicians to establish their creative matrices until the generation of an original mathematical product ${ }^{5}$, mainly in the elaboration of theorem proofs and demonstrations or even in the elaboration of new theories that expand or innovate the field of mathematics, by means of both answered and open questions (cf. Mendes, 2015).

In the case of a theorem proof, for example, the creative procedure requires two distinct steps: the choice of suitable hypotheses, so that the resulting conclusion has value within a broader theory, and the actual deduction of the hypotheses to establish the proof of the examined theorem. It is important to understand that the initial choice is also a step in the formulation of the possibilities to operate creatively in the demonstration, because, depending on the path one chooses, the trajectories, guidelines and final results can vary and, sometimes, may not meet the interests initially desired or imagined. It is in activities as complex as the proof or demonstration of theorems or relationships between mathematical principles that mathematical creativity comes to the fore.

\footnotetext{
${ }^{4}$ Duncan, D. E. (1999). Calendar: the epic of humanity to determine a true and exact year. Rio de Janeiro, Ediouro.

${ }^{5}$ These classificatory categories are created from the studies I develop concerning the history of mathematics and will be explored more consistently in the book Epistemologies on mathematical creativity and creation: evidence extracted from the history of mathematics. To be released in 2020.
} 
For creativity to be activated in mathematical creation, there is no need for a formal theory to be available. What matters is the attention to be paid to the most active part of creativity in terms of regeneration and renewal. In this sense, what is essential in the mathematical creation process is that the person involved has their cognitive activity well activated in terms of mental preparation so that they can relate previously unrelated concepts, and thus be able to establish the largest possible number of qualified combinations around their object of creation. The results observed by researchers show that creation often occurs after the relaxation that follows a period of intense activity involving a heightened state of awareness the context and of all the constituent parts of the process, thus enabling the establishment of relationships between the ideas that have emerged.

Based on the ideas of Ervynck (1991), I consider the following as the main ingredients of mathematical creativity: study practice that produces familiarity with the subject, intuition of the deep structure of the individual, imagination and inspiration in other studies known in any area of knowledge, and results, framed in a formal deductive structure.

With an explanation similar to Ervynck's proposal (1991) for the three stages of creation, Efraim Fischbein (1987) establishes that the creative process involves intuition and creative mathematical reasoning, whose procedural movement involves imagination, representation and mathematical abstraction as a complex that makes up constructive mathematical activity. According to Fischbein (1987), this type of activity involves three components: intuitive, algorithmic and formal. The intuitive component concerns the way we use imagination, visualization, all our human experiences, and even our biological characteristics in the elaboration of mathematical thinking. It is through intuition that we are able to interpret mathematical concepts and talk about different mathematical situations. The algorithmic component refers directly to the use of algorithms in the symbolic representation of the same thought. The formal component concerns the use of a formal language which makes mathematical ideas accessible only to individuals who have mastered that language. This component is seen as a superior form of expression of mathematics, as well as an advanced form of knowledge, thus making it the chosen vessel to present school mathematics.

In the course of the next sections of this article, I will take the concepts of creativity, creation, invention as interconnected concepts in order to highlight historical moments in which I understand that a creative act in mathematics occurred during the history of mathematical creation. In this movement, I will highlight aspects relatively connected to the acts of creation of each knowledge and its implications in the development of new creations in time and space, such as, for example, the metric relations in the right triangle, the Pythagorean theorem, the notion of abscissa and ordinate, the distance between two points, the modulus of a vector, the complex number modulus, among other concepts and relations expressed by the conceptual extension, originated from the relations between the measurements of the sides of any right triangle.

\section{CREATIVITY AND MATHEMATICAL CREATION IN HISTORY}

Regarding the processes of creativity and mathematical creation in history, I emphasize initially that classical Greek tradition referred to the word mathematics as learning or science. Over the years, this meaning was extended to special fields of learning, generating several definitions for mathematics. Its disadvantage, however, was to ignore intuition, mathematical practices and non-standard methods that have emerged throughout history. Such methods and practices advanced by stimulating the creation of symbols and patterns of formal representation for certain mathematical concepts, which represented a process of creativity and, consequently, the creation of new types of mathematics. The conclusions reached by the use of new symbolic patterns and codes began to impose certain combination laws based on this mathematical writing, leading scholars of the subject to seek to adapt themselves to a codified literature and to the multiple conditions of representation of mathematical ideas and practices offered by them, giving rise to several ways of representing mathematical thoughts and practices.

Since Antiquity, practices related to Astronomy and measurements seem to have been one of the main factors that led to the encouragement of studies related to mathematics. The ancient Babylonians, for example, generated their mathematical studies in the exploration of celestial bodies, whereas the ancient Egyptians were stimulated by the measurement of the earth, which influenced the initial development of geometry (Barthélemy, 2003). Throughout the history of mathematical ideas and practices, the attempt to correct possible errors perceived in works already announced in academic circles or even related to mathematical practices in cultural, technical and technological contexts, made mathematical characters like Francois Viète (1540-1603), René Descartes (1596-1650), Pierre de Fermat (1601-1665), Isaac Newton (1643-1727), Gottfried Wilhelm Leibniz (1646-1716), among others, develop their creativities in an attempt to solve perceived errors. Many questions came from these attempts, giving rise to new conceptual and formal aspects for the different types of mathematics, triggering a wide network of scientific and, later, pedagogical connections.

The creativity attributed to these historical moments meant research, re-elaboration, interpretation and, consequently, the emergence of new mathematical explanations. The continuous investigations, inquiries and revisions added to mathematical knowledge at different times in history constituted an extremely enriching instrument (Cf. Mendes 2015). The beauty and insight provided by the new results and statements were fundamental to understand how much mathematical curiosity can influence the process of mathematical invention and discovery. For this reason, the investigation of errors in the work of mathematicians has often been the basis of mathematical creativity in the history of this knowledge.

Perhaps this was the creative advance from a stage zero to a stage 1 (Ervynck, 1991) as expressed by Viète's work (1540-1603) on algebraic processes for the treatment of equations and their numerical and geometric relations with the objective of detaching rhetorical algebra towards symbolic algebra and algebraic geometry. In 1630, JL Vaulezard was one of those who wished to contribute to the dissemination the of new ideas on how to approach mathematical problematizations through algebra, what led him to translate Viète's key work in this field, titled La nouvelle algèbre de Viète (The New Algebra of Viète), from Latin into French, 
and publish it in Paris. Among the information described by Vaulezard (1630; 1986), there are explanations that Viète took the decisive step that paved the way for his successors, among which we highlight René Descartes.

From what Vaulezard presents, I understand that in Viète's works we can identify studies on pure geometry, based on the Euclidean tradition, related to his astronomical concerns, but mainly the innovative works in algebra and in trigonometry that is structured in the relations between his geometry and his algebra. The format he chooses to approach the subjects clearly shows the analytical character of his studies, placing them in a more theoretically advanced stage than those of Girolamo Cardano and a less advanced stage than the innovation brought to the subject by Descartes (1596-1650) and Fermat (1601 -1665).

It is in this line of reasoning that I will consider the discussions about the mistakes made in the historical development of geometry as stimulators of the works developed by Ptolemy, Apollonius, Pappus and others, causing decisive mathematical creation in the 17th century, with the work of René Descartes (1637) about the discourse on the method and the solution of Pappus' problem, thus creating a new branch in mathematics, related to the solution of geometric problems, relying on equation solving, which subsequently triggered the studies that originated analytical geometry. This seems to be a unique example of creativity in the history of mathematical creation.

Thus, Descartes' geometry can be considered an example of creativity in the history of mathematical creation. For Jullien (1996), Descartes' Geometry considered what was unreadable, for it was not an easy-to-understand approach for the seventeenthcentury reader, and today, almost four centuries later, still constitutes a challenge for students. To accomplish that, Descartes used to say that "it is impossible to represent a figure devoid of any extension", that is, when one gets to know the body, its extension, the figures and the movements, it would be possible, then, to know through the unique understanding, but, much better, through understanding aided by the imagination (Rule XII) ${ }^{6}$. It is true that the extension can receive a sense according to which it is separated from the body; considered in this way, it does not correspond to any idea in fantasy. It arises from the competence of pure understanding.

Therefore, the lines of Cartesian geometry are not separated from material objects. This does not in any way entail that, after reflecting on them, one should embrace the set of determinations of the bodies, since even they can turn their attention to a specific mode of the thing, to one (or two) of its dimensions, abstracting from the rest of its determinations (see Rule XIV). From these observations, it follows that understanding, during its geometric investigations, reserves a place for imagination, an auxiliary that is paramount. It is the need for some characters of imagination, which are necessary to produce geometric knowledge. If it were just a reproductive, excessively realistic kind of imagination, it would quickly bring confusing. Decartes accused the ancient thinkers of using this conception of imagination and tried to imagine another explanatory option for the problem (cf. Lewis, 1996; Guinsburg, Romano, \& Cunha, 2010).

Likewise, an exercise in creativity regarding the relations between curves and their arithmetic or algebraic representations was addressed by Frege in a conference given in 1891 (cf. Frege, 1971), when he stated that the analytical geometry method originated from works such as that of René Descartes (1637) provided a way to intuitively represent the values of a function for different arguments, for when we consider the argument as the numerical value of an abscissa and the corresponding value of the function as the numerical value of a point's ordinate, we obtain a set of points that presents itself to intuition (in common cases) as a curve. Any point on the curve corresponds to an argument along with the function's associated value. This exercise of interpreting the concept of function can be considered as being in stage 2, that corresponds to the conceptual and constructive creative activities that, according to Ervynck (1991), demonstrate that mathematical creation was moving towards the development of a mathematical theory regarding functions, that is, it was advancing in its formalization level towards a functional theory, as was evidenced in the work of Paul Du Bois-Reymond (1887), when he stated his general function theory as metaphysics and theory of the fundamental mathematical concepts on this subject, based on the concepts of greatness, limit, argument, and function, already announced in previous works, such as the ones D'Alembert accomplished in the 18th century.

To better outline the discussions we proposed so far, in the next section of this article I will present a synthesis of some creative curiosities extracted from the history of infinitesimal calculus, in view of their importance in understanding the processes of creativity and innovation in the conceptual development related to infinitesimal calculus and the installation of new ways of reading phenomena that greatly contributed to the development of current science and technology.

\section{CREATIVITY IN THE HISTORY OF INFINITESIMAL CALCULATION}

Several historical studies carried out since the second half of the 19th century point out that the infinitesimal calculus has its origin in the intuitive conception that the Greeks had about the mathematical notions of continuum, infinite and limit, as well as in their difficulties to formulate these notions explicitly. Studies indicate that the creative process in search of these formulations connected all three of these notions, which were more adequately established from the 19th century onwards, when mathematicians who wished to systematize the progress that had been achieved until then returned to the foundational bases of infinitesimal calculus to establish the construction of this part of mathematics on solid ground in the form of creative action in mathematics. Historical information was extremely important for such formulations to be creatively established. Next, we will point out some flashes of the discussion about this creative process.

\footnotetext{
${ }^{6}$ These rules refer to a part of the work of René Descartes, called Regulae ad directionem ingenii (Rules for the Direction of the Spirit), an incomplete work published posthumously in 1701.
} 


\section{From the Unimagined to the Concept of Limit}

The concepts that involve relations between numbers and geometric quantities, with a historical emphasis on the discovery of irrational numbers already known to us, have advanced widely and deeply from the beginnings of human society to the most sophisticated mathematical and linguistic explanations expressed today. This whole creative process characterizes an objective that has gradually established itself since the Ancient Greeks, when they sowed the first seeds of the relations between numbers and quantities, numbers and measurements, numbers and proportions, until it originated the principles of measurement theory, which culminated in the studies on contemporary mathematics. In this movement that comes from the Greeks, discussions arose that promoted the cognitive improvement of creative processes that led scholars in this field to establish the numerical body of irrational numbers, the concepts of variable, function, limit and continuity of a function.

It is a creative movement that, according to Einstein (1993), asserts that imagination is more important than knowledge, because knowledge has its limits, which can be overcome by creative actions. This creative movement that involves relations between numbers and quantities has triggered a process of creative conceptual development throughout our history, characterizing its roads and labyrinths, which have been overcome, step by step, by scholars who dedicate themselves to this object of knowledge.

In the trajectory of the roads and labyrinths referring to the concept of limit, there is another fundamental highlight that corresponds to the violation of the infinite by means of Zeno's paradoxes, which subsequently caused the emergence of conceptual evidence of the concrete uncertainty of the number, leading to the structuring of the concept of limit and its later definition as a mathematical entity that configures the numerical field in a broader way, although a quite abstract one. In this paradox, Achilles and the turtle are opposed to the infinite divisibility of space and time. Achilles running with the turtle is a player who advances the turtle. As he travels the distance that separates him from the turtle's starting point, the turtle advances in its own turn; the distance between Achilles and the turtle is reduced, of course, but the turtle retains the advantage. As Achilles covers the new distance that separates him from the turtle, the same thing happens with the turtle. If space is infinitely divisible, Achilles will never be able to catch the turtle. What is at stake in this paradox is the difficulty of intuitively conceiving that this sum can be equal to a finite grader.

In this sense it is possible to admit that the present argument is even more explicit in the dichotomy: before being able to cross an entire line, a mobile object must first cover half of that line, then half of the half and so on to infinity. It is a metaphorical creative process established to make explicit the notion of limit at a time when the supporting concepts of the central argument about this concept were not yet well established in this part of the field of mathematics.

However, it was evident how creative Zeno was creative in this epistemic explanation. In this regard, we can notice that modern notions of limit and convergence of a series allow us to state that, in a way, the difference between Achilles and the turtle becomes smaller than a given number $\varepsilon$, which will be chosen as small as one wishes. Thus, these relations reflect the consequences of asking questions about the immeasurability of certain measured quantities, whose discussions led to the emergence of exhaustion methods, through which the negation of the infinite was intended, until the emergence of the scientific concept of limit.

At the end of the 19th century, according to Du Bois-Reymond (1887, P. 135), the scientific concept of limit came to be understood as a primitive abstraction of both internal and external perceptions, leading to representations generated absolutely by means of thought processes, thus originating the scientific concept of limit. That is, sometimes it refers to limits of sequences of individual value, as the most common case in the mathematics of Antiquity (for example, in the matters related to the circumference of the circle considered as the limit of the perimeter of polygons and in the quadratures of Archimedes), sometimes limit means sequences of continuous values, as in the matter of the tangent (secant limit), and many limits of infinitesimal calculus which arose from the matter of the tangent. However, in the abstract theory of magnitudes (measures), the existence of the limit is always drawn simply and without discussing the primitive concept of limit. What is the object of a scientific problem, is only the nature of the quantity sequences, which have a limit, and these are practical rules of the convergence criterion of infinite operations under very limited premises, rather than a general principle covering all possible sequences of quantities.

As they were discussed later in history, the creative processes related to the methods of curve squaring and of the cubature of surfaces, were elaborated and experienced by several of history's most prominent mathematicians such as Eudoxo, Euclides, Archimedes, Cavalieri, Fermat, Pascal, among others, who dedicated many of their studies to this subject, out of creative curiosity or out of creativity due to the need to find solutions to challenging problems that arose in the socio-cultural contexts of each era.

Historically, the reproduction of the exhaustion method was also accomplished in Arabian cultures, as there is information regarding the translation of manuscripts on studies related to the sphere and the cylinder, by Thabit Ibn Qurra (836-901), and studies on the squaring of the parable. In this historical movement about creativity in the creation of the conceptual pillars of infinitesimal calculus, the period of the Middle Ages is considered the age of respectability, because, if the Arabs dominated the Greek exhaustion method since the 9th century and developed approximate methods, the Medieval West ignored the Archimedean works almost completely ${ }^{7}$.

However, speculations about the infinite, the infinitely small and the nature of the continuum, revived the interest in the problem of the infinite and prepared the acceptance of infinitesimal considerations in the 17th century. In this sense, the most representative medieval work of the medieval creative process, considered a theoretical progress on the quantitative study of variability, was carried out by Nicolas Oresme (1325-1382), about a geometric demonstration of the trajectory of a mobile object

\footnotetext{
${ }^{7}$ See Dahan-Dalmedico; Peiffer (1986), referenced in the Bibliography.
} 
in uniformly accelerated movement in the same space as a second mobile object, with constant speed equal to the mean between the extreme speeds of the first one (Figure 1).

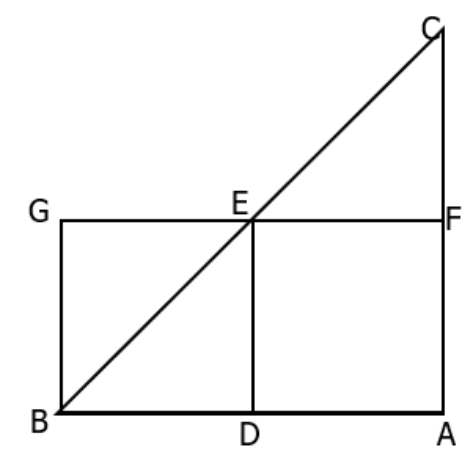

Figure 1. Geometric demonstration of the trajectory of a mobile object in uniformly accelerated movement

For this, he used a graphical representation, one of the first, of the functional relationships that link time and speed. In the 14th century, together with studies on the movement of bodies it was the main theme of studies and research in the schools of natural philosophy, where mathematicians of these schools such as Roger Bacon (1214-1294) and Thomas Bradwardine (12901349) were also involved in studies that aimed at modeling physical phenomena and apply the evidence of the relationship between speed, strength, and weather resistance, all this, of course, geometrically. They quantified phenomena such as speed, heat, density, and the quality of the advances may vary continuously.

These dynamics concerning the development of creativity in the creation of the concept of variable, function, and limit have their epistemology advanced since Classical Antiquity as a stage zero or as a stage of preliminary technical trend, followed by stage 1 of embryonic algorithmic activities established by Nicolas Oresme in the Middle Ages. Such a creative process, historically constructed by philosophers and mathematicians, points to a dynamic that converged to the expansion of the inventive exercises that took the history of the development of the concept of function to stage 2, concerning the creative activities (conceptual, constructive ones), characterized by function models.

Still under the questions about the creation of processes that could explain principles related to the variability in the measurement of quantities of different order, other works based on the Greek tradition were carried out creatively, like those of Simon Stevin (1548-1620), until Johann Kepler (1571 -1630) abandoned these classic methods and resorted to more intuitive methods inspired by the work of Nicolas de Cusa (1440; 2003). Thus, he compared the circle to a regular polygon with an infinite number of sides and calculated its area by summing the areas of infinitesimal triangles, having the sides of the polygon as bases and the center of the circle as the vertex of these polygons.

From what was evidenced in historical information, Kepler did not explain the conceptions on which he based his way of proceeding. In general, he used to decompose surfaces and volumes into an infinity of infinitesimal elements of the same dimensions, but at times he used the language of the indivisibles and did not distinguish an area. He used to apply his method to the calculation of revolution volumes (sphere, cone, cylinder, etc.).

According to historical information identified in Dahan-Dalmedico and Peiffer (1986), Kepler's influence was very great and Stereometria doliorum (1615), in which he indicated a procedure for calculating the contents of wine barrels, served as a model for about half century. According to the authors, Kepler also considered maximum and minimum problems, which he solved by means of numerical considerations, establishing tables, which allowed him to compare the volumes of a solid when its dimensions vary.

Thus, he showed that the cube is the largest rectangular parallelepiped with a square base inscribed in a sphere and that, of all rectilinear cylinders with an equal diagonal, the cylinder whose height and diameter are in the relationship $\frac{1}{\sqrt{2}}$ has a maximum volume. Examining these tables, he observed that in the vicinity of the largest volume, the volume variation is smaller for a given dimension variation. This idea reappeared later in the 17th century in Fermat's work. Subsequently, other studies and creative investments spearheaded by several mathematicians and physicists from the 16th and 17th century gave rise to innovations added to the exhaustion method, thus originating the methods of the indivisibles. Among these, we highlight the works of Cavalieri, Evangelista Torricelli (1608-1647), and Giles-Personne Roberval (1602-1675).

Considered as a creative example of the extension of Archimedes' ideas, the geometry of Cavalieri's indivisibles can be considered as an investigative exploration and an creativity exercise in mathematical creation, enunciated in two of his works: Geometria Indivisibilibus continuorum nova quadam ratione promota (Geometry of the continuous by indivisibles presented by new methods), and also, Exercitationes geometricae sex (Six geometric exercises).

Published in 1635, the Geometria indivisibilibus continuorum nova quadam ratione promota consists of seven books. Book I deals with the elementary geometry of plane and solid shapes, and deals especially with rotation solids: cylinders and general cones (having any closed curve per guideline), as well as the sections of these solids. In Book II Cavalieri develops the first method of indivisibles, the "collective method" and demonstrates some general theorems about collections of indivisibles. It does not contain any definition of an indivisible, but it characterizes the infinitesimal elements of which surfaces and volumes are composed.

He considers a plane shape as the set of its lines and conceives the solid as composed of an "indefinite" number of parallel planes. The author assumes that a line is formed of points like a string of pearls, that a surface is formed by lines like a fabric of threads and that a volume is composed of a plane in the same manner as a book is composed of pages. This creative imagination 
is what drives the whole method created by Cavalieri, since this was the preliminary stage for his mathematical creativity to be established.

Thus, his creativity tried to overcome the difficulty of the time in relation to the sum of an infinite number of elements. Unlike Galileo, Cavalieri did not speculate about the nature of the infinite, rather, he used to avoid calculating the area of a surface as the sum of all indivisible constituents. Instead, he used to determine the proportion of the areas of shapes whose indivisibles were in a constant relationship. Therefore, Cavalieri initially invested creatively to show that the area of the parallelogram is twice the area of each of the triangles obtained by drawing the diagonal of the parallelogram (Figure 2).

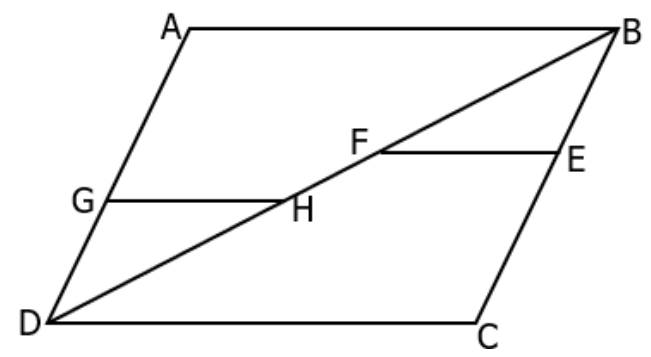

Figure 2. Representation of the area of the parallelogram by Cavalieri

If $\mathrm{G}$ and $\mathrm{E}$ are two points such that $\mathrm{GD}=\mathrm{BE}$, and if $\mathrm{GH}$ and $\mathrm{FE}$ are drawn parallel to $\mathrm{DC}$, then the segments $\mathrm{GH}$ and $\mathrm{FE}$ are congruent (equal). The sum of all the lines in the $A D B$ triangle will be, therefore, equal to the sum of all lines in the $D B C$ triangle and the two triangles will have equal areas. The sum of the lines of the ABCD parallelogram is twice the sum of the lines of one of the two triangles.

In Books III, IV and V he applies the previous theorems to the quadratures and cubatures of figures related to the conic sections. Book VI is dedicated to the quadrature of the spiral, but it also obtains results on paraboloids and spheroids. He ends Geometria by presenting a new method of indivisibles: the distributive method.

The Exercitationes is composed of six books. In Book I, Cavalieri offers a reduced and simplified view of the collective method. Book II accomplishes a new presentation of the distributive method. Book III draws on Cavalieri's reactions to Güldin's harsh criticism. Book IV generalizes the collective method of indivisibles, applying himself to algebraic curves of degree greater than two, obtaining a result equivalent to the basic quadrature, currently represented by

$$
\int_{0}^{a} x^{n} d x=\frac{a^{n+1}}{n+1}
$$

Developing a work very similar to that of Cavalieri, Torricelli perfected the method of the indivisibles and used it, for example, to establish that the volume of the infinitely long solid generated by the rotation of a part of the equilateral hyperbola around its asymptote is finite (Figure 3). Torricelli considered cylinders indivisible, whereas Cavalieri's were invariably plane.

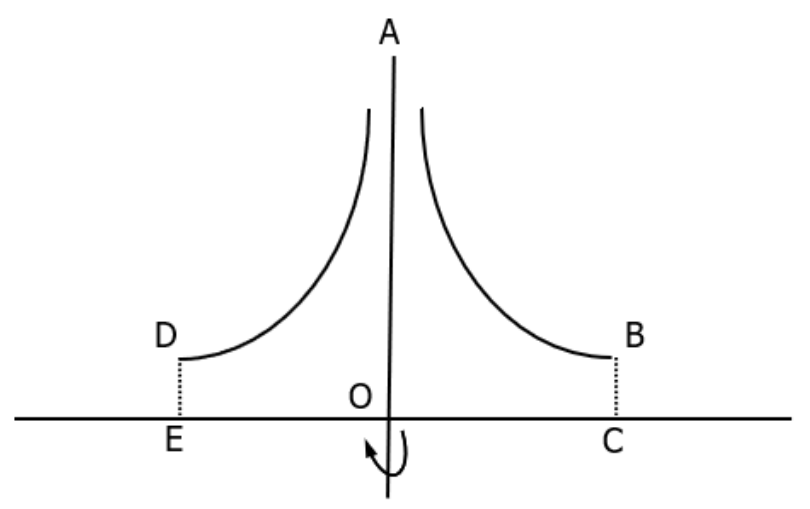

Figure 3. Part of an equilateral hyperbola around its asymptote

Regardless of Cavalieri's method, Roberval developed a method of indivisibles which, instead of relying on Cavalieri's geometric approach, returned to Stevin's quasi-arithmetic point of view, which included infinite arithmetic series. Unlike Cavalieri, who argued that the surface was made up of lines, Roberval claimed that it was made up of surfaces, for he assured that there were an infinite number of holes that occupied an infinity of infinite small areas that made up the total area. The infinity of areas represented the infinity of small solids which, together, made up the whole solid.

Thus, Roberval used the notion of an indivisible to determine the area under a cycloid arc. The cycloid is conceived as a curve described by the point of a circle that rolls without sliding in a direct line. To Pascal, this curve was nothing more than the path that the nail of a wheel makes in the air when it rolls from its Common movement. He also affirmed that it was the most elegant curve of the 17th century and that it allowed surveyors to update the new techniques that were the source of infinitesimal calculus.

In this movement around the geometry of indivisibles, it is possible to identify that creativity in mathematical creation mobilized imagination, intuition, and experimentation in order to constitute models of algorithmic and symbolic representation through geometry, algebraic, and the proto-concepts of function that existed until then. Thus, the three stages mentioned by Ervynck (1991) are highlighted once again to characterize the creation movement of the infinitesimal calculus. 
The expansion of the studies that led to the outbreak of infinitesimal methods in the 17th century deserved to be highlighted with the creativity we find in the works on the quadrature of curves, carried out by Fermat and Pascal and due to the approaches given to tangent problems, in order to point out the connection between quadratures and tangents. Fermat (1601-1665) mastered the Archimedean methods perfectly, and from 1636 he studied parables of type $y=a x^{m}, m$ being a positive integer. Later, he established a new, more general process which he made known in a manuscript titled On the formation and simplification of equations of places, ... His method, uniform and constant, allowed him to investigate the quadrature (to determine the area) of all parables and hyperboles (except one). I will describe a quick summary of the principle of the parable $y=x^{2}$ example, without using Fermat's notation and language.

Fermat's mathematical creativity led him to establish the following: to calculate the area under the parable between 0 e $x$, Fermat chose $x, e x, e^{2} x, e^{3} x, \ldots$ on the $x$ axis, where $e$ is a number smaller than 1 , as shown in Figure 4.

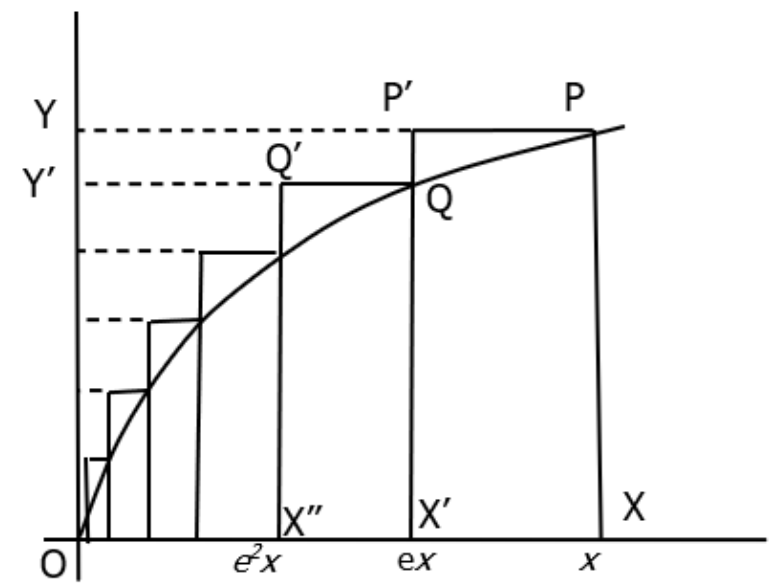

Figure 4. Fermat's mathematical creativity to represent the area under the parable between $\mathrm{O}$ and $\mathrm{x}$

At these points, he raised the ordinates and constructed rectangles, the areas of which he determined the value, using what he called the "specific properties" of the parable (that is, for us, his equation $\mathrm{y}^{2}=\mathrm{x}$ ).

The area of the first rectangle X'XPP 'is equal to the difference between the area of the OXPY rectangle of the $\mathrm{x}$ base and the height of $\sqrt{x}$ and the area of the rectangle OX'P'Y, ex base, and the height of $\sqrt{x}$ and, therefore $x \cdot \sqrt{x}-e x \cdot \sqrt{x}=x \cdot \sqrt{x}(1-e)$.

Similarly, the area of the second rectangle X' $X$ 'QQ' is:

ex. $\sqrt{e x}-e^{2} x \cdot \sqrt{e x}=e x \sqrt{e x}(1-e)$.

The areas of the rectangles will then form an infinite geometric progression of ratio $e . \sqrt{e}$.

Fermat's process constituted real progress in comparison with the others, since it systematically applied the new point of view of analytical geometry, originated in the work created and published by Descartes in 1637. The results obtained by Fermat generated criticism and comments, but his work went ahead due to the continuity given by other scholars, who later dedicated themselves to the subject.

Pascal (1623-1662), in perfecting the quadrature methods proposed by his predecessors, underestimated the importance of new analytical processes. According to Dahan-Dalmedico and Peiffer (1986), his works belong in the geometric tradition established by Arquimedes, Cavalieri and Torricelli, and constitute, in some way, the culmination of their work. I believe that Pascal's mathematical creativity was very distinctly opposed to Cavalieri's conception, which was also of a geometric nature like Archimedes'. Thus, Pascal creatively replaced Cavalieri's intuitive arguments with arithmetic arguments about a series.

Therefore, in the mathematical creation of the quadrature of his parable, Pascal constructed rectangles on abscissae chosen in an arithmetic progression, of $d$ distance, calculated their $\mathrm{d}$. (nd $)^{2}$ areas and determined the $\mathrm{S}$ sum as follows:

$$
\begin{aligned}
& S=d \cdot d^{2}+d \cdot(2 d)^{2}+d .(3 d)^{2}+\ldots+d .(n d)^{2}, \\
& S=d^{3}+4 d^{3}+9 d^{3}+\ldots+n^{2} d^{3} \\
& S=d^{3}\left(1+2^{2}+3^{2}+\ldots+n^{2}\right), \\
& S=d^{3} \cdot\left[\frac{n}{6}(n+1)(2 n+1)\right]=d^{3}\left(\frac{n^{3}}{3}+\frac{n^{2}}{2}+\frac{n}{6}\right) .
\end{aligned}
$$

If the number of rectangles were to increase indefinitely, Pascal allowed himself to neglect the $n^{2} / 2$ and $n / 6$ terms related to the first one and the sum of the areas of the rectangles would be equal to $S=d^{3} \frac{n^{3}}{3}=\frac{(n d)^{3}}{3}=\frac{x^{3}}{3}$. This omission of terms has its origin in Pascal's parallelism between the geometric and arithmetic points of view, which made him compare the geometric indivisible to arithmetic zero. This parallel became systematic in the infinitesimal methods of the second half of the 17 th century.

Another aspect of creative curiosity regarding the history of differential and integral calculus is the problem of tangents whose conception dates back to Antiquity, and which is highlighted in the works of Archimedes, Apollonius, Torricelli and Roberval, as a conceptual extension of the investigations on the relations between the parables' and circumference's secants and tangents in search of the construction of the largest polygons inscribed and the largest one circumscribed in the circumference, in order to solve the quadrature problem. This problem extended to other different curves of the circumference, thus contributing to future works such as those of Descartes, Newton and Leibniz. 
Therefore, it was still in the seventeenth century, that the creativity involved in the creation of infinitesimal calculus had its greatest prominence, in the works of Isaac Newton with infinitesimal conception, his method of fluxions and the method of the first and last reasons, which was simply the embryo of the ideas about the derivative definition by means of the use of infinitesimal rate of change, which was later established based on the concept of limit, as we currently define in calculus courses.

Regarding Isaac Newton, I consider it important to highlight that he studied at Trinity College in Cambridge, where he encountered the works of Descartes, Galileo Galilei (1564-1642), John Wallis and Isaac Barrow (1630-1677), among others, but had to interrupt his studies between 1665 and 1666 because of the plague that hit London at that time. These two years of enforced leisure were very creative (creative leisure, as defined by Domenico de Masi), because it was at this time that Newton laid the foundations of his mechanics and his optics and conceived the principles of fluxions theory. Returning to Cambridge in 1669, Newton soon replaced Barrow in the mathematics chair, who had remained until 1665.

There are only three writings by Newton on infinitesimal calculus. They were not published until the early 18 th century and could only have had a slight influence. Newton, who had a paralyzing fear of critics, hesitated throughout his life to publish the results of his research. A first and brief mention of his fluxions' theory appeared in 1687 in his famous work on mechanics Philosophiae naturalis principia mathematica (Mathematical Principles of Natural Philosophy), which had considerable repercussions. The propositions about velocities, acceleration, tangents, and curvatures, established in geometric terms, in this work, strongly motivated Newton in his research on infinitesimal calculus.

For Newton's commentators, the main authors who influenced him were Aristotle (c. 385-323 a. C.), Kepler, Galileo, Descartes, and Christiaan Huygens (1629-1695), since these were the authors who contributed the most to the development of this celebrated work elaborated by Newton. For at least a century, the ideas disseminated in this work stimulated the creation of new analytical processes necessary to solve the general problems addressed in it involving the subject.

For Dahan-Dalmedico and Peiffer (1986), three different conceptions about infinitesimal calculus appear in Newton's work. The first is the one that was influenced by Barrow and Wallis, in which Newton operates with infinitely small quantities he calls tempo (instant) and which are equivalent to Fermat's infinitesimal additions or increments. He also uses area moments and its quadrature depends on it. Newton assumes the area of a surface bounded by the representative curve of a function $f$, the coordinate axes and the ordinate $y$ a given point of abscissa $x$ and considers the infinitesimal area moment as annotated quantity o (Figure 5).

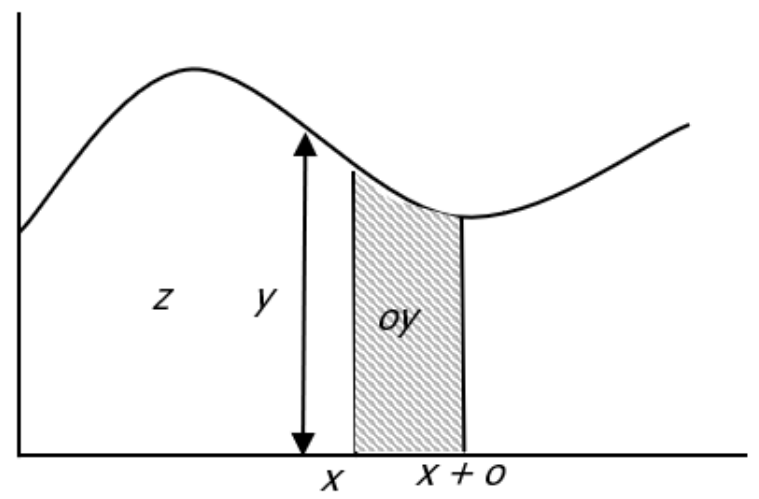

Figure 5. Newton's representation for an infinitesimal area taken on a curve

It calculates the instantaneous rate of change of the area at the abscissa $x$ point, that is, the derivative, and finds that it is equal to the $y$ ordinate of point $x$ of the curve's abscissa. Thus, if the given area is expressed by

$z=\left(\frac{n}{m+n}\right) \cdot a^{\frac{m+n}{n}}$, its rate of change will be $y=a x^{\frac{m}{n}}$.

Inversely, Newton determined the area under the curve given by the equation $y=f(x)$, inverting the derivation operations, that is, calculating the indefinite of $f(x)$. He did not add more infinitesimal quantities as in the previous processes, but placed the derivative in the central focus of his studies and favored the indefinite integral over the defined integral. From 1669 onwards, the relationship between the quadratures and the derivations was clearly established by Newton, although his search for clear definitions of what derived and integral would be had not yet been fully realized, mainly with regard to infinitesimal increments.

Thus, it was around 1671 that Newton introduced the Fluxions Method in his work, in which he considered the mathematical quantities generated by continuous augmentation. To establish his method on solid ground, Newton looked for inspiration in the model of theoretical mechanics and introduced time as the universal variable of all functional correspondence. He was not interested in time itself, but in its uniform flow.

Based on this method, the mathematical creation process triggered new innovative links materialized with the elaboration and enunciation of the method of the first and last reasons concerning the quadrature of curves. From that moment on, there were several creative ideas about the concept of limit as an adequate parameter for the enunciation of the concept of derivative, which would bring about other concepts such as discontinuity. At that moment, a new advance in the creative stages of infinitesimal calculus creation was evident, according to the parameters defined by Ervynck (1991).

Leibniz's entrance in this journey was similar, with his work on sums and subtractions expressed by means of the formalism represented by the universal characteristic through which he defended a single linguistic approach having mathematics as a starting point. Either independently from each other or not, they invented convenient creative algorithmic procedures and 
recognized the connections between apparently isolated problems. Therefore, we are able to consider Newton and Leibniz the founders of infinitesimal calculus to the extent that the generality of their methods and techniques turned infinitesimal analysis into a branch of study that was autonomous and independent from geometry.

The creative advance of this branch of mathematics went ahead towards the processes that, according to Dahan-Dalmedico and Peiffer (1986), configure the Foundations Essays, which include the mathematical creations of Leonhard Euler (1707-1783), Jean le Rond d'Alembert, and Joseph Louis Lagrange, whose conclusions led to the elucidation of the basic concepts and to a first theory on (integral) integration, as well as to the insertion of the rigor of Weirstrass' mathematical creations, to the construction of real numbers, and to Dedekind's systematization of irrational numbers, which led the processes of mathematical creativity to innovations and renovations that enabled the expansion of mathematical theories in their relations with the concept of function and its approach as the central axis of mathematics teaching in the 20th century.

Such creative and renewing innovations of mathematical theories, which I referred to in the previous paragraph, contributed to the fact that the pedagogical guidelines formulated and proposed for the teaching of calculus in polytechnic schools and universities, and, later on, in secondary school, unfolded in parameters for the expansion of didactic creations in school manuals in the second half of the 19th century and in the first half of the 20th century.

The creative innovation in the creation of the calculus that was to be taught pointed in two directions. On the one hand there was a logical-analytical approach, which shaped mathematical discourse in the form of the knowledge that was to be taught and the knowledge needed to teach this mathematics at school, possibly based on the ideas of Euclides, Euler, Lagrange, Cauchy, Weierstrass, among others. On the other hand, there was a synthetic-intuitive approach based on the formatting of speeches based on the experiments of Arquimedes, Descartes, Newton, Taylor, Riemann and Felix Klein.

Concerning Klein, evidence was marked at the beginning of the 20th century when mathematicians and mathematical educators realized that there was a discontinuity between secondary and higher education, based on the criticism expressed by Felix Klein when he identified the students' lack of knowledge about functions and infinitesimal calculus when they entered higher education courses. Thus, he proposed the insertion of these subjects in secondary education.

In Brazil, this innovation was consolidated by the reform proposed by Benjamin Constant between 1890 and 1891, when he created the Notions of Infinitesimal Calculus chair, to be taught in the last years of high school, in view of the basic general culture formation which was the aim of secondary school teaching. Many experts in Mathematics teaching considered that there was a great advantage in the insertion of calculus' notions in secondary school because it made possible the intertwining of notions and symbols related to knowledges such as, for example, Mathematics and Physics, having an intuitive teaching process as a starting point, which would balance formalism and rigor in the teacher's presentations. The argument for the teaching of functions was the same.

\section{CREATIVITY IN THE HISTORY OF THE CONCEPT OF FUNCTION}

The idea of the relationship between quantities is as ancient as mathematics itself. But what have been the paths that conducted it from such a vague sense to the theoretical-contemporary conception of a function or application, which establishes correspondence between elements of one set with one element of another set? And what were the different representations of the concept of function throughout our history, as a concept that is central to the development of analysis? These are some of the questions that moved the creative exercise in mathematics towards the development of this theme, which we call function conceptual.

Since Antiquity, the idea of function is exposed as a relationship between quantities in Babylonian mathematics, in sexagesimal tables, in the relationships between squares and square roots, cubes and cube roots, among other aspects, such as measures referring to ancient astronomy, particularly in stellar, solar lunar, and other planets' observation. The Pythagoreans' classical attributions in the relations between measures related to geometry, astronomy, such as the astronomical tables present in Ptolemy's Almagest are also from this ancient period.

The notions of function from the correspondences between measures of quantities and values are a modern conception. However, the intuitive idea about variable quantity is very old. In this sense, the practical types of mathematics that emerged from Archimedes' work refer to the concepts of variable, limit, and, consequently, to the concept of function. The most important part of this conceptual dynamic is the creative process established since those remote times until the present, in order to creatively reinvent the concept and broaden the epistemological horizons on the subject.

The dynamics concerning the creative development in the creation of the concept of function and its epistemology advanced in classical antiquity from stage zero, also called preliminary technical trend stage, as mentioned by Ervynck (1991), followed by stage 1 of embryonic algorithmic activities established by Nicolau de Oresme until the Oxford and Paris schools, with the first representations being extremely important theoretical moments characterized by studies of the movements and the trajectories of physical bodies.

The notion of form and its variation and intensity was among the most discussed logical-philosophical notions in this period, and these ideas gained new explanations from Oresme, with the support of the geometric representation of measures and their variability expressed as follows: everything what varies, which can be measured or not, can be imagined as a continuous quantity represented by a line segment (cf. Clagett, 1968; Fernández; Castro, 2007). These were his statements for the concepts regarding his theory of latitudes and longitude of (geometric) forms; a kind of proto-theory of the relations between abscissas and ordinates, 
which emerged as an innovation at the time to explain the relationship between variable magnitudes, that is, the notions of variation, later called fluxions by Isaac Newton and discussed analytically in Descartes' geometry in 1637.

Such a creative process, historically constructed by philosophers and mathematicians, points to a dynamics that converged to the expansion of the inventive exercises that took the history of the development of the concept of function to stage 2 , concerning the creative activities (conceptual, constructive) characterized by function models, such as the logarithmic function originated in John Napier's work (1550-1817) and in René Descartes's (1637) work on geometric curves, as well as the algebraic functions that represented such curves.

From Descartes' ideas it can be considered that the creative activities on the concept of function advanced towards the infinite algorithms originated in the method John Walis presented in his Arithmetica Infinitorum (Infinitesimal arithmetic), which gave rise to new studies towards a new mathematical object established by the principles and laws of variations, which was accomplished by the works of Newton and Leibniz, expanded this concept in both extension and meaning, and resumed the embryos planted by Archimedes, Cavalieri, Oresme and Descartes ${ }^{8}$. It was, therefore, a continuation of the stage of the creative activities which advanced towards the establishment of algebraic analysis produced, mainly, in the 18th century, by means of the works of Euler and Daniel Bernoulli (1700-1782), who would later open spaces for the phenomenon of multiform functions.

Another example of creativity in the creation of infinitesimal calculus appears in the work of Colin Maclaurin, published at the end of the first half of the 18th century, circa 1742, under the title $A$ treatise of fluxions in two books, whose original title was $A$ Complete System of Fluxions with their Application to the most Considerable Problems in Geometry and Natural Philosophy). In this work, Maclaurin advocates and provides a geometric structure for Newton's fluxions method, and presents solutions to several geometric problems, shows that the stable numbers for a homogeneous rotating fluid mass are revolution ellipsoids and provides, for the first time, the correct theory to distinguish between maximums and minimums in general, pointing out the importance of distinction in the theory of multiple points of curves. Moreover, he makes a detailed discussion of infinite series and includes the special case of the Taylor series.

The epistemological basis of the work is the exhaustion method based on book 12 of Euclid's Elements, the method for comparison and area of plane, circular, and elliptical shapes, following with a general theorem for the description of shapes originated in conical sections and some of Archimedes' propositions on spheres, spheroids, parable quadrature, Archimedes' and Pappus' spiral, other ancient methods related to the exhaustion principles as well as main aspects regarding the methods of the indivisibles and infinitesimals. It was clear that the author resorted to information on the historical development of mathematical concepts that were considered essential to relate aspects concerning the central theme of the book: the ideas of fluxions. In this sense, the author discusses the elements of the fluxions method and demonstrates, based on several mathematical practices established by the ancient geometers.

It is in this creative movement that Euler published Introductio in analysin infinitorum (Introduction to infinitesimal analysis) in 1748 , which began to shape the concept differently and added new algorithmic configurations to the subject, so as to show an inventive spirit, endowed with a very safe and very reliable technique to obtain new and varied results. Thus, the concept of function in Euler's mathematics began to contribute greatly to the development of algebraic analysis and revealed a yet unknown phenomenon about functions and their formal classification as algebraic functions (rational: integer and fractional and irrational: explicit and implicit) and transcendent functions like the trigonometric, logarithmic, exponential ones, etc. (Figure 6).

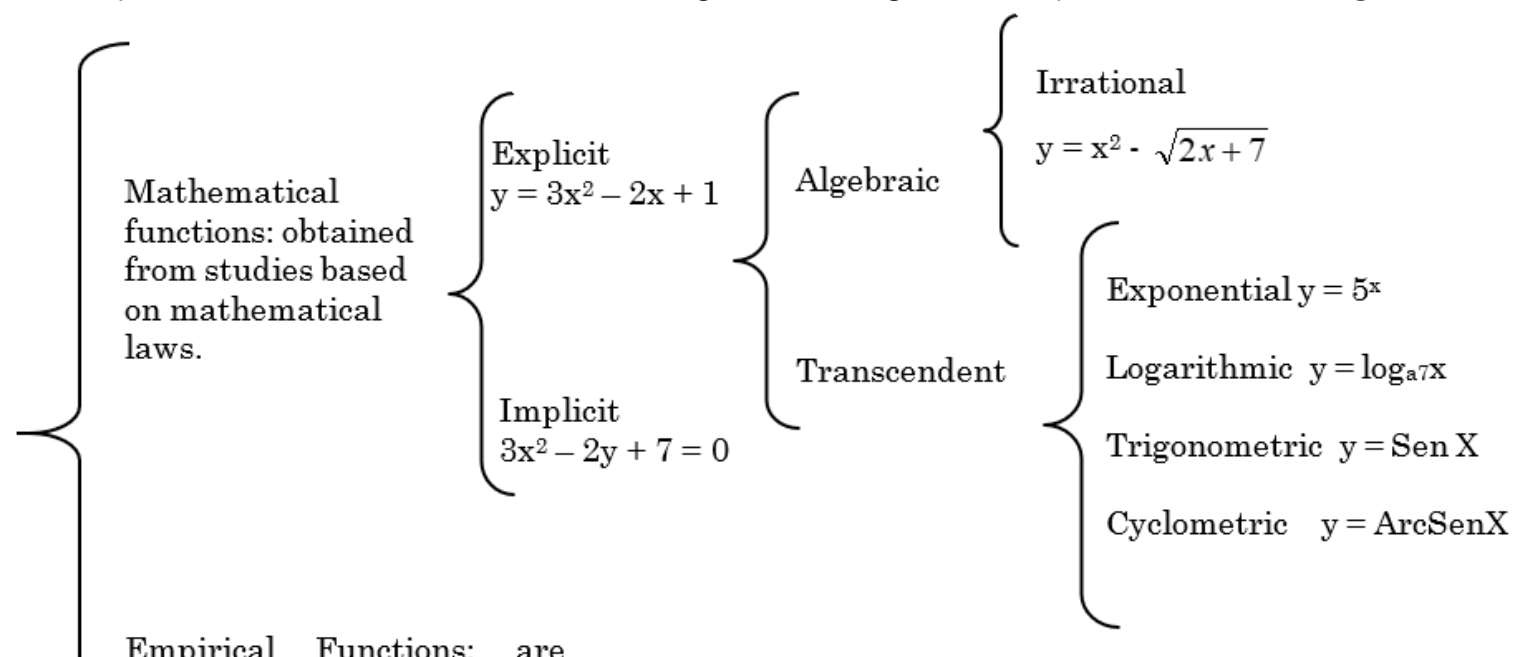

Empirical Functions: are

deduced from the observation

of a phenomenon.

Figure 6. Classification of functions

\footnotetext{
${ }^{8}$ Regarding mathematical creativity in this work by John Wallis I mention the doctoral thesis of Gabriela Lucheze de Oliveira Lopes (2017) entitled The mathematical creativity of John Wallis in the work Arithmetica Infinitorum: contributions to teaching differential and integral calculus in the mathematics degree, mentioned in the references at the end of this article.
} 
Continuing dynamics of this movement, the concept of function took on new form in its creative process in the context of mathematical creation (invention) throughout the 18th and 19th centuries, in the sense attributed by Henri Poincare and Jacques Hadamard to intuition as an imaginative exercise for mathematical production, the basis of which presupposes the existence of cognitive action (internal processes) to process the understanding and explanation of the ways of existing (being) in the outside world and the organization of these processes in sociocultural communication.

Concretely, the teaching proposals that emerged advocated the insertion of functional knowledge and infinitesimal calculus in basic education by means of a proposal similar to those of Ervynck (1991) in its three creativity stages, centered on the ability to solve problems and/or develop thinking in structures, taking into account the peculiar logical-deductive nature of functional knowledge and the adequacy of the concepts of variability (variable), relationship between quantities, interdependence, correspondence between number and shape, algebraic and graphical representation of curves, etc.

Within the scope of school knowledge, the process of creating a more general conceptual elaboration on function came to be represented under a stage called creative activity, stage 2, as suggested by Ervynck (1991). It is a more advanced creative process that involves a movement of conceptual and constructive establishment. An example of this kind of creative elaboration appears in the epistemological discussions covered in the book Théorie Générale des Fonctions, when its author, Bois-Reymond (1887, p. 170-171), asserts that the general concept of function, as developed throughout the 19th century, configured a new analysis in that period, and did not require, for example, the definition of the function for any much greater argument value, because to maintain greater generality, one could imagine a law, according to which, in ranges of arguments fixed by it, one could arbitrarily choose a point and place the value of the function at that point, according to the manner in which the value of the argument was settled in single integer intervals for values of the function.

Another example of this movement that I consider characteristic of the stage related to creative activity is evidenced in a 1904 publication, titled What is a function?, in which Gottlob Frege (1848-1925), examines two proposed concepts to explain that a function denotes the notion of calculus expression and the notion of variable. He establishes logical connections between variables, functions and their representations by means of signs and meanings involving numbers, operational signs, numerical signs, that is, argument signs, as well as function signs, and their logical ordering in the structure of an equation as an algebraicfunctional representation (cf. Frege, 1971).

Frege states also that even when a function - complemented by a number - provides a number, we call the latter the value of the function, of which the first number is the argument, where we read the equation $y=f(x)$ as: $y$ is a function of $x$. According to Frege, this is a double flaw. First, we translate the equals-sign as a copula; then, we confuse the function with its value for an argument. These flaws gave rise to the opinion that the function is a number, be it a variable or an indeterminate number. We have seen that these numbers do not exist and that functions are fundamentally different from numbers.

Thus, he highlights that there is an inappropriate use of language, stating that for the sake of brevity, imprecise expressions were introduced in mathematical language; these expressions, in turn, created problems in the mind and allowed the formulation of defective definitions. Mathematics should really be a model of logical clarity. In fact, it may be that no other science contains more fallacious expressions, therefore more fallacious thoughts, in its textbooks than mathematical sciences. Logical correctness should never be sacrificed for brevity of expression. That is why it is extremely important to develop a mathematical language that combines extreme precision with the greatest possible conciseness (Frege, 1971).

This movement of re-creation or creative adaptation of the concept of function for the elaboration of a general theory, as proposed by Bois-Reymond, pointed towards a new way of approaching the subject in the context of higher education and, later, in secondary education, with suggestions of a general theory that comprehensively covered the teaching of fields related to the subfields of mathematics. Thus, the idea of functionality or functional thinking became one of the themes addressed politically by Felix Klein at the beginning of the 20th century, with the justification that it was necessary to insert such a theme in secondary education because it was an aspect of current mathematics (at the time), in order to offer better conditions for the mathematical formation of students in view of their scientific future (cf. Klein, 1905). Hence the triggering of creative exercises for the production of functional knowledge to be taught and ways of approaching this functional knowledge.

\section{Creativity in the Functional Approach to the Teaching of Mathematics}

At the end of the 19th century, the notions of function began to play a decisive role in the organization of school mathematics, strongly influencing the curricula of mathematics teaching. The approach Felix Klein proposed at that time for the insertion of the concept of function in secondary and higher education, had a strong influence in the main centers of Mathematical studies and universities, in order to result in the creation of school disciplines related to Mathematics with emphasis in aspects related to functionality (cf. Klein, 1905, 1998).

In a study on the process of integrating functional theories in school mathematics' curricula in Brazil, Braga (2003), highlights that the main statements guiding Felix Klein's (1927; 1931) proposal for the insertion of a functional approach in secondary education, were justified by him, due to the need of introducing notions of Infinitesimal Calculus among the contents of secondary school in correlation with the inclusion of functional theory as the base of approach for several subjects of secondary school mathematics (logarithmic function, exponential function, trigonometric function, etc). Likewise, he considered that it was also important to introduce this functional thinking to students since the first school years, and thus it would be possible to foster the connections between the different branches of Mathematics, based on the idea of movement in Geometry, as proposed by Descartes (1637).

Felix Klein's proposal was meant to value induction and intuition, including as heuristic resources, in order to gain knowledge that could, at the proper occasion, be systematized, as advocated by Poincaré in his conventionalist intuitionist philosophy, and 
his principles were based on the arguments presented in the volumes of Elementary Mathematics from a Higher Point of View (Klein, $1927,1931)$, based on courses that elaborated for and aimed at mathematics teachers.

In this context, the concept of function centered on the ideas of variability and interdependence we mentioned earlier, which were triggered by studies on the development of calculus, and went on to be understood as the unifying principle of Mathematics' 9 teaching. In this regard, in 1893, during an International Congress of Mathematics, held in Chicago, Felix Klein presented to the teachers a proposal that defended the convenience of adopting the concept of function as the central unifying axis of Mathematics teaching.

Subsequently, in 1904 he persisted in the theme at a conference in Götingen, when he argued favorably about the main objective of Mathematics teaching in secondary school, by suggesting that Mathematics teaching should prioritize a correlation between various mathematical themes that make up the intellectual training of students, such as the notion of function and its geometric and analytical (graphical) representation, supported by the idea of dependence between two variable quantities, such as was being announced since the work of Nicolau de Oresme up until Euler's, that is, a process of functional creation that already had a development trajectory for more than four centuries, through creative processing (cf. Roxo, 1937).

Thus, the concept of function came to be understood as one of the main objects of Mathematics teaching. Therefore, there would be a need for a reorganization of Mathematical contents in secondary and higher education, in view of the new proposals for didactic and conceptual approaches to this subject, which was considered of decisive importance for the scientific and technological development of the twentieth century, that had just begun.

It was, therefore, a creative innovation in the teaching of Mathematics that was based on the mathematical creation developed over more than four centuries and which had started to exercise essential importance in the organization of a disciplination process of Mathematics, which brought about the production of professional knowledge related to Mathematics teaching, that is, the knowledge to be taught and the knowledge needed to teach mathematics in secondary school, Valente (2017) emphasize, when he mentioned the conceptual and pedagogical discussions proposed by Euclides Roxo in the first decades of the 20th century.

It was with this mindset that the first decades of the twentieth century saw the rise of proposals and disciplinary guidelines for curricular reorientation, innovations in teaching programs, and the rearrangement of the contents of textbooks or school manuals for secondary school Mathematics, based on the creative innovations arising from the new Mathematics characterized by functional thinking. It was an approach to Mathematics teaching based on the concept of function, as a perspective for the establishment of connections between mathematical knowledge through that concept, with the object of preparing students for higher education. This functional approach was based on the epistemological disclosures enunciated by Felix Klein for this knowledge transformation, that was coming from function studies in Europe throughout the 19th century as a conceptual consequence of the development of infinitesimal calculus, as mentioned above.

The challenges to the teacher's creativity in secondary and higher education courses, as well as to the authors of Mathematics textbooks and school manuals, lay in establishing conceptual and didactic connections among Mathematical contents by means of a functional approach that transversalized the disciplinary knowledge of the course, in order to prepare students for higher education. Thus, some objectives were established for a Mathematics teaching centered on functional thinking, whose epistemological guideline recognized that the dependence on a variable quantity in relation to another variable quantity was one of the aspects that mathematics teachers should consider as the most important part of the functional thinking that was to be stimulated as an important construction in students' learning of school mathematics.

Consequently, the proposal was to determine the nature of the relationships between these variables and the ways in which they could be algebraically expressed through tables and graphs, in order to enable the achievement of the objectives of this new mathematics teaching, centered on the development of the various characteristics of functional thinking, as previously mentioned. Thus, it was considered a priority to use algebraic expressions to represent the concept of function, with emphasis on establishing the definition of variable or variation and the meaning of this concept as application and transformation.

The evidence of creativity on this subject was established mainly in the connections between thinking, languages, and problematizations with characteristics of transversal or interdisciplinary actions for this subject, since problems related to the most diverse areas of knowledge, in addition to mathematics, were used to express both thinking and functional languages. In this dynamic, creative processes were established in order to be inserted into curricular, conceptual and didactic activities in the teaching of mathematics in secondary school.

In this sense, Euclides Roxo (1937) considered that the development of function notions was completely accessible to secondary school students, provided that such notions were developed procedurally, slowly and progressively, in all years of secondary school and properly configured as a unifying element for all the parts of mathematics. Consequently, there were several comments on the functionality principle that transversalized the whole of mathematics teaching, as a creative aspect that transformed the ways of thinking and doing mathematics in secondary school at the time, although it was strongly criticized by many experts of that period.

Another highlight pointed out by Roxo (1937) was about the need to discuss the historical-epistemological development of the concept of function within the scope of the students' mathematical and mastery for the benefit of their conceptual expansion upon entering university, as well as the relationship of this concept in the physical, natural, and social sciences. We can notice that it is from these new conceptual and didactic guidelines that the knowledge concerning function teaching and learning in secondary school started to follow a new trajectory as a school discipline that brought about curricular changes and rearrangements in the ways of dealing with the subject in school manuals, as was mentioned earlier.

\footnotetext{
${ }^{9}$ For further details on the subject, see Roxo (1937) mentioned in the references at the end of this article.
} 


\section{FINAL REFLECTIONS AND FUTURE PROJECTIONS}

Based on the ideas about a pedagogy of creativity, proposed by Martins (2000), we identified an environment conducive to creativity in the studies involving history in mathematics classes, one in which the teacher provides students with multiple exercises that involve raising questions, elaborating and testing hypotheses, disagreements and the critical evaluation of proposed historical situations or investigated historical facts, provided they are given time to think and develop creative ideas and reflections on the historical themes involved.

For such exercises to be successfully carried out, it is necessary, however, to determine a creative thinking that productively explores intuitive (imagination, invention, intuition), operative (logic, chain of ideas), and symbolic (perception, attribution of meanings) activities as creative skill indicators for the creative exploration of historical information in mathematics classroom activities, among other actions that provoke cognitive challenges for those who use investigation as a learning resource.

These are central aspects of the didactic referrals I have been proposing and experimenting with mathematics teachers in their initial and continuing education since the 1990s, in undergraduate Mathematics and Pedagogy courses I worked with, especially when it comes to the use of history in mathematics teaching, that is, a central priority for historical investigation in the sense of using the epistemological development of mathematics as a cognitive trigger to creatively learn from the use of historical information as a cognition agent (Mendes, 2006, 2015).

It is a matter of emphasizing the exploration of historical mathematical facts in order to acquire learning based on past processes of mathematics reinvention so as to provide mathematical learning in the present, with the aim of moving towards the mathematics of the future. In other words, it means understanding the questions raised and the challenges overcome in the past, their critical appraisals and reinventions until the present in order to realize that discontinuity can still be investigated for the constitution of new knowledge.

In this sense, my reflections are combined with the proposals suggested by Sternberg and Williams (2003), according to which creative ideas are as new as they are valuable, but creative work requires the application and balance of three capacities that can all be developed:

1. Synthetic capacity: it is what we typically think of as creativity, that is, the ability to generate new and interesting ideas, when thinking by means of synthesis, relating things that other people do not know.

2. Analytical capacity: typically considered a capacity of developing critical, analytical, and evaluative thinking about ideas in order to point out the implications of a creative idea and test it.

3. Practical ability: the ability to turn theory into practice and abstract ideas into practical realizations, in order to convince others about their potential importance.

However, it is necessary to imagine other creative possibilities and practice other experiences that can establish a balance between these capacities in order to develop actions that promote investigative and creative learning in mathematics.

A practical suggestion of concrete actions the teacher may accomplish is to diversify the ways of investigating the history of mathematics with the objective of obtaining teaching materials, and to identify the variety of types of didactic approaches available for use in the classroom, based on information researched by others. It is also important to exercise the reinvention of teaching activities proposed in old and recent school manuals, textbooks or other class resources, as well as contents from articles and works of didactic-scientific events that deal with the theme, or yet, approaches to historical socio-cultural practices evidenced in studies indirectly related to the history of mathematics in connection with art, science, technologies, and other branches of human culture, such as elements from religious knowledge and professional practices.

In short, it is a matter of exercising and exploring multiple historical socio-cultural practices bearing in mind conceptual and didactic objectives to include them in mathematics classes. In this perspective, my reflections point out that it is possible that these were the capacities and experiments that accompanied most of the actions that conducted the creative spirit of those who developed definitive ideas in mathematics throughout its historical process.

Thus, conceptual and didactic explorations of the history of mathematics in the classroom must be operationalized based on these evidences of capacities that can sharpen the students creativity in all stages of teaching activities, guiding them in maintaining a balance between those three capabilities mentioned earlier.

Therefore, in order to practice such creativity development exercises in historical explorations in mathematics classes, teachers also need to develop themselves creatively, that is, to devote themselves to the challenge of appropriating these skills when employing the historical development of mathematical ideas to address mathematical topics such as some of those we mentioned in this article and the most diverse studies that operate the conceptual organization of the mathematics we teach.

It is, therefore, in this movement that we need to take into account the suggestions for proposed strategies presented by Sternberg and Williams (2003) regarding the development of creativity in terms of establishing creative teaching models through techniques that lead students to a creative learning, that is, the exercise of raising and questioning hypotheses so as to define and redefine concepts and problematizations through the crossing of ideas extracted from the history of the conceptual development of mathematics they are expected to learn.

Author contributions: All authors have sufficiently contributed to the study, and agreed with the results and conclusions.

Funding: No funding source is reported for this study.

Declaration of interest: No conflict of interest is declared by authors. 


\section{REFERENCES}

Araújo, T. (2009). Criatividade na educação [Creativity in education]. Imprensa Oficial.

Barthélemy, G. (2003). 2500 anos de Matemática: A evolução das ideias [2500 years of Mathematics: The evolution of ideas]. (Trans. I. Andrade). Instituto Piaget.

Bohm, D. (2011). Sobre a criatividade (Trans. R. de Cássia Gomes). Publisher of UNESP.

Bois-Reymond, P. (1887). Théorie générale des fonctions [General theory of functions]. Niçoise Printing.

Braga, C. (2003). Processo inicial de disciplinarização de função na matemática do ensino secundário brasileiro [Initial process of disciplining function in the mathematics of Brazilian secondary education]. (Masters' thesis in Mathematics Education). Pontifíca Universidade Católica - PUCSP.

Carroll, L (1879). Euclid and his Modern Rivals. Macmillan and Co.

Carroll, L. (1885). A tangled tale. Macmillan and Co.

Carroll, L. (1886). Alice's adventures underground. Macmillan and Co.

Clagett, M. (Ed.). (1968) Nicole oresme and the medieval geometry of qualities and motions. University of Wisconsin Press.

Cortez, J. (2004). Lunário e Prognóstico Perpétuo [Lunar and Perpetual Prognosi]. Lello Publishers.

Csikszentmihalyi, M. (1996). Creatividad: El fluiry la psicologia del descubrimiento y la invención [Creativity: Flow and the Psychology of Discovery and Invention]. Paidós.

Cusa, N. (2003). A Douta Ignorância [The Doubtful Ignorance]. Calouste Gulbenkian Foundation.

Dahan-Dalmedico, A., \& Peiffer, J. (1986). Une histoirie des mathématiques: Routes et dédales [A History of Mathematics: Roads and Mazes]. Éditions du Seuil.

Davis, P. J., \& Hersh, R. (1995). A experiência Matemática [The Mathematical Experience]. Gradiva.

De Masi, D. (2000). O ócio criativo [Creative leisure]. (Interview to Maria Serena Palieri). Sextante.

De Masi, D. (2003). Criatividade e grupos criativos [Creativity and creative groups] (Trans. de L. Manzi). Sextante.

Descartes, R. (1637). La Géométrie [Geometry]. In Discours de la méthode. Flammarion.

Duncan, D. E. (1999). Calendário: a epopéia da humanidade para determinar um ano verdadeiro e exato [Calendar: the epic of humanity to determine a true and accurate year]. Rio de Janeiro, Ediouro.

Einstein, A. (1993). Escritos da Maturidade [Maturity Writings]. (Trans. M. Luiza X. de A. Borges) (5th Ed.). Nova Fronteira.

Ervynck, G. (1991). Mathematical Creativity. In D. Tall (Ed.), Advanced mathematical thinking (pp. 42-53). Kluwer Academic Publishers. https://doi.org/10.1007/0-306-47203-1_3

Euclides. (2009). Os Elementos [The Elements] (Trans. I. Bicudo). UNESP Publisher.

Fernández, C. S., \& Castro, C. V. (2007). Las funciones, Un paseo por su historia [The functions, A walk through its history]. Nivola.

Fischbein, E. (1987). Intuition in Science and Mathematics. Na Educational Approach. D. Reidel Publishing Company.

Frege, G. (1971). Écrits logiques et philosophiques [Logical and philosophical writings]. Éditions du Seuil.

Gonçalves-Maia, R. (2011). Ciência, pós-ciência, metaciência: tradição, inovação e renovação [Science, post-science, metacience: tradition, innovation and renewal]. Ed. Livraria da Física (Contexts of Science Collection).

Guinsburg, J., Romano, R., \& Cunha, N. (Ed.). (2010) Descartes: obras escolhidas [Descartes: chosen works]. Perspectivas.

Hadamard, J. (2009). Psicologia da invenção matemática (Trans. E. dos Santos Abreu). Contraponto.

Jullien, V. (1996). Descartes. La Géométrie de 1637. Presses universitaires de France. (Collection Philosophies, 76).

Kasner, E., \& Newman, J. (1968). Matemática e Imaginação [Mathematics and Imagination] (Trans. J. Fortes). Zahar Publishers.

Klein, F. (1905, 1998). De la enseñanza de las ciencias matemáticas y físicas em las universidades (Translation of an article published by D. M. V. Johresberitcht, 1905). Educación Matemática, 10(1), 133-139.

Klein, F. (1927). Matemática Elemental Desde um Punto de Vista Superior [Elemental Mathematics From a Top View Point] (vol. 1). Mathematical Library Collection, Madrid.

Klein, F. (1931). Matemática Elemental Desde um Punto de Vista Superior [Elemental Mathematics From a Top View Point] (vol. 2). Mathematical Library Collection, Madrid.

Kline, M. (1985). Matemáticas. La pérdida de la certidumbre [Math. the loss of certainty]. Siglo XXI de España Publishers.

Lakatos, I. (1978). A Lógica do descobrimento matemático: provas e refutações (Trans. N. C. Caixeiro). Zahar Publishers.

Lopes, G. L. O (2017). A criatividade matemática de John Wallis na obra Arithmetica Infinitorum: contribuições para ensino de cálculo diferencial e integral na licenciatura em matemática [The mathematical creativity of John Wallis in the work Arithmetica Infinitorum: contributions to the teaching of differential and integral calculus in the degree in mathematics] (Doctoral dissertation in Education), Education Center, Federal University of Rio Grande do Norte, Natal.

Maclaurin, C. (1742). A treatise of fluxions in two books. T. W. and T. Ruddimans.

Martins, V. M. T. (2000). Para uma pedagogia da criatividade [Towards a pedagogy of creativity]. Work proposals. Asa Publishers. (Research and Practice Notebooks, 12). 
Maturana, H. R., \& Varela, F. J. (2001). A árvore do conhecimento: As bases biológicas da compreensão humana [The tree of knowledge: The biological bases of human understanding] (Trans. H. Mariotti \& L. Diskin). Palas Athena.

Mendes, I. A. (2006). A investigação histórica como agente da cognição matemática na sala de aula [Historical research as an agent of mathematical cognition in the classroom]. In I. A. Mendes, J. A. Fossa, \& J. E. N. Valdez (Eds.), A História como um agente de cognição na Educação Matemática. Editora Sulina.

Mendes, I. A. (2015). História da Matemática no ensino: entre trajetórias profissionais, epistemologias e pesquisas [History of Mathematics in teaching: between professional trajectories, epistemologies and research]. LF editorial.

Mendes, I. A. (2019). Criatividade na história da criação matemática: potencialidades para o trabalho do professor [Creativity in the history of mathematical creation: potentialities for the teacher's work]. SBEM Pará.

Moles, A. A. (1998). La création scientifique [Scientific creation] (1st Ed.). Kister.

Moles, A. A. (2007). A criação científica [The scientific creation]. Perspectiva. (Studies Collection - Philosophy of Science).

Moles, A. A., \& Caude, R. (1970). Créativité et méthodes d'innovation das l'entreprise [Creativity and innovation methods in the company]. Fayard-Mame.

Perkins, D. (2003). La bañera de Arquímedes y otras historias del descubrimiento científico: El arte del pensamiento creativo [The Archimedean Bath and Other Stories of Scientific Discovery: The Art of Creative Thinking] (Trans. G. Solana). Paidós.

Poincaré, H. (1908, 1999). Science et Methode [Science and Method]. Paris: Flammarion, 1908. Reed. Paris: Kimé.

Rodis-Lewis, G. (1996). Descartes: uma biografia [Descartes: a biography] (Trans. J. A. D. Melo). Records.

Roxo, E. (1937). A Matemática na Educação Secundária [Mathematics in Secondary Education]. Companhia Editora Nacional.

Serres, M. (2008). Ramos [Branches] (Trans. E. de Assis Carvalho \& M. P. Bosco). Bertrand Brasil.

Steiner, G. (2011). Gramáticas de la Creación [Grammars of Creation] (Trans. A. Alonso \& C. G. Rodriguez). Ediciones Siruela.

Sternberg, R. J., \& Williams, W. M. (2000). Como desenvolver a criatividade do aluno [How to develop student creativity]. Asa Publishers.

Valente, W. R. (2017). A matemática a ensinar e a matemática para ensinar [Mathematics to teach and mathematics to teach]. In R. Hofetetter \& W. R. Valente (Ed.), Saberes em (trans)formação: tema central da formação de professores. Editora Livraria da Física.

Vaulezard, J. L. (1986). La nouvelle algèbre de M. Viète. Suivi de Zététiques. Paris: 1630. Reed. Corpus des oeuvres philosophiques en langue française [M. Viète's new algebra. Zetetics follow-up. Paris: 1630. Reed. Corpus of philosophical works in French]. Fayard.

Vergani, T. (2009). A criatividade como destino: transdisciplinaridade, cultura e educação [Creativity as a destination: transdisciplinarity, culture and education]. Ed. Livraria da Física (Contexts of Science Collection). 